NUREG/CR-2079

PNL-3691

\title{
Analysis of Credible Accidents for Argonaut Reactors
}

Prepared by S. C. Hawley, Pacific Northwest Laboratory

R. L. Kathren, Pacific Northwest Laboratory

M. A. Robkin, University of Washington

Pacific Northwest Laboratory

Operated by

Battelle Memorial Institute

Prepared for

U.S. Nuclear Regulatory

Commission 


\section{NOTICE}

This report was prepared as an account of work sponsored by an agency of the United States Government. Neither the United States Government nor any agency thereof, or any of their employees, makes any warranty, expressed or implied, or assumes any legal liability or responsibility for any third party's use, or the results of such use, of any information, apparatus product or process disclosed in this report, or represents that its use by such third party would not infringe privately owned rights.

GPO Sales Program

Division of Technical Information and Document Control

U. S. Nuclear Regulatory Commission Washington, D. C. 20555

Printed copy price: $\$ 4.00$

and 


\section{Analysis of Credible Accidents for Argonaut Reactors}

Manuscript Completed: April 1981

Date Published: April 1981

Prepared by

S. C. Hawley, Pacific Northwest Laboratory

R. L. Kathren, Pacific Northwest Laboratory

M. A. Robkin, University of Washington

Pacific Northwest Laboratory

Richland, WA 99352

Prepared for

Division of Systems Integration

Office of Nuclear Reactor Regulation

U.S. Nuclear Regulatory Commission

Washington, D.C. 20555

NRC FIN B2313 


\section{ABSTRACT}

Five areas of potential accidents have been evaluated for the Argonaut-UTR reactors. They are:

- insertion of excess reactivity

- catastrophic rearrangement of the core

- explosive chenical reaction

- graphite fire

- fuel-handling accident.

A nuclear excursion resulting from the rapid insertion of the maximum available excess reactivity would produce only $12 \mathrm{MWs}$ which is insufficient to cause fuel melting even with conservative assumptions. Although precise structural rearrangement of the core would create a potential hazard, it is simply not credible to assume that such an arrangement would result from the forces of an earthquake or other catastrophic event. Even damage to the fuel from falling debris or other objects is unlikely given the normal reactor structure. An explosion from a metal-water reaction could not occur because there is no credible source of sufficient energy to initiate the reaction. A graphite fire could conceivably create sone damage to the reactor but not enough to melt any fuel or initiate a metal-water reaction. The only credible accident involving offsite doses was determined to be a fuel-handling accident which, given highly conservative assumptions, would produce a whole-body dose equivalent of 2 rem from noble gas immersion and a lifetime dose equivalent commitment to the thyroid of 43 rem from radioiodines. 



\section{SUMMARY}

The original safety analyses on the Argonaut-UTR reactor class are more than 20 years old and predate certain relevant experimental studies and analyses of the SPERT-I test data. Moreover, the UTR design differs from that of the original Argonaut, and certain important parameters such as fuel enrichment, nominal fuel loading, and neutron lifetime have also been changed.

Following a literature review, five broad areas of potential accidents were evaluated for the Argonaut-UTR reactors as a class. These are: 1) reactivity or supercriticality accident; 2) catastrophic rearrangement or flooding of the core; 3) chemical explosion; 4) graphite fire; and 5) a fuel-handling accident. Sabotage or delifberately induced events were not considered. The results of these analyses are sumarized below.

For a criticality burst or nuclear excursion, the maximum available excess reactivity would be $2.6 \% \Delta k / k$, which would require a coolant/moderator temperature of $4^{\circ} \mathrm{C}$ and control blades totally removed from the core. The maximum energy release from such an event would be 12 Ms or about $4 \times 10^{17}$ fissions. Even using the most conservative assumptions, this anount of energy would be insufficient to melt the fuel or breach the cladding integrity; the maximum hot-spot temperature would be $74^{\circ} \mathrm{C}$ below the melting point of the cladding.

Catastrophic rearrangement of the core, as from a major earthquake, could alter the spacing of the fuel boxes and reduce the minimum critical mass from 3.2 to $1.9 \mathrm{~kg}$ of ${ }^{235} \mathrm{U}$, assuming that the moderator remained in the core. Such a "perfect" rearrangement, however, would be virtually impossible. If flooding of the core took place during a major structural rearrangement, the total reactivity of the core could be raised by about $14 \% \Delta k / k$, again assuming ideal conditions and such improbable events as collapse of the control blade shrouds with the blades removed. Because of the finite time required for flooding, the reactivity change would occur relatively slowly rather than as a pulse, and the amount of damage from the nuclear excursion would be small in comparison to that from the event initiating the mechanical rearrangement. 
The chemical reaction of aluminum and water, which generates explosive gas, would require high temperatures or the presence of finely divided aluminum. The energy necessary to initiate the reaction would be at least twice that available from an inadvertent supercriticality, and hence the reaction is not considered credible.

A graphite fire can be postulated from many different scenarios, including a major building fire. Given an initiating event, such a fire could result in core melting and fission product release. However, except for a major building conflagration with essentially no suppression, itself a highly unlikely event, there appear to be no credible initiating events.

The only credible accident involving offsite doses would be a fuel-handling accident, which, given highly conservative assumptions, would produce a wholebody dose equivalent of 2 rem from noble gases and a lifetime dose-equivalent cormitment of 43 rem to the thyroid. 
CONTENTS

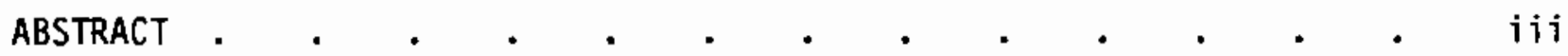

SUMMARY • . . . . . . . . . . . . . . . .

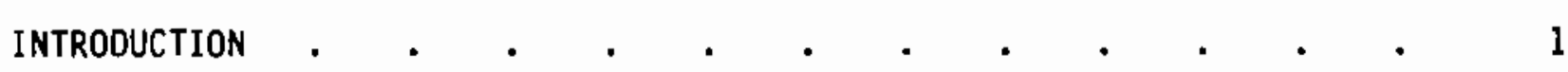

PAST HAZARDS ANALYSES OF THE ARGONAUT REACTOR.$\quad \cdot \quad \cdot \quad \cdot 3$

NEED FOR NEW HAZARDS ANALYSIS $. \quad . \quad . \quad . \quad$. . . . . 7

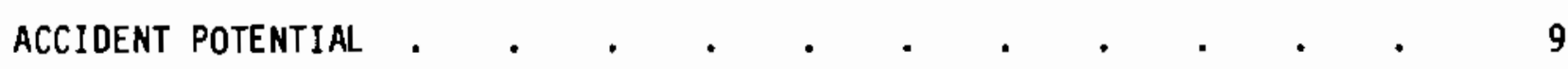

BASIC ARGONAUT DESIGN AND OPERATING CHARACTERISTICS $\cdot \cdots$

DEVELOPMENT OF REALISTIC ACCIDENT SEQUENCES

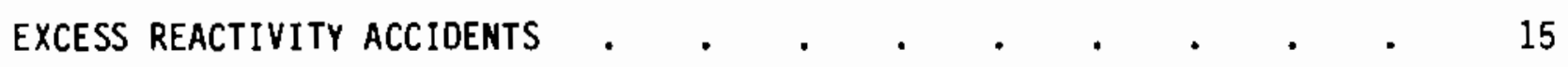

MAXIMUM EXCESS REACTIVITY . . . . . . . . . . 15

MAXIMUM ENERGY RELEASE

FUEL PLATE HEAT CAPACITY AND TEMPERATURE RISE $\quad \cdot \quad \cdot \quad \cdot \quad . \quad 18$

CATASTROPHIC MECHANICAL REARRANGEMENT OR FLOODING • . • . . . 22

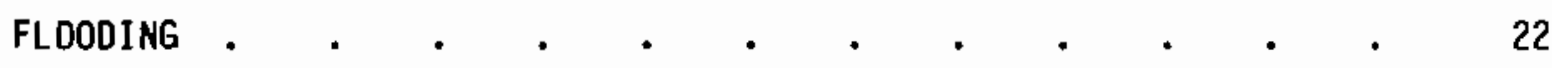

URANIUM CRITICAL MASS $. \quad . \quad . \quad . \quad . \quad . \quad . \quad . \quad . \quad 23$

STRUCTURAL REARRANGEMENT AND FLOODING

CORE-CRUSHING ACCIDENT

THEORETICAL VERIFICATION OF REACTIVITY CHANGES $\quad \cdot \quad \cdot \quad \cdot \quad \cdot \quad 27$

EXPLDSIVE CHEMICAL REACTIONS • . . . . . . . . . . . . . 28

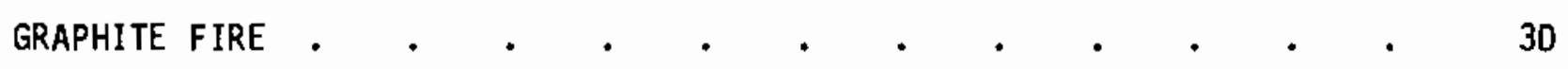

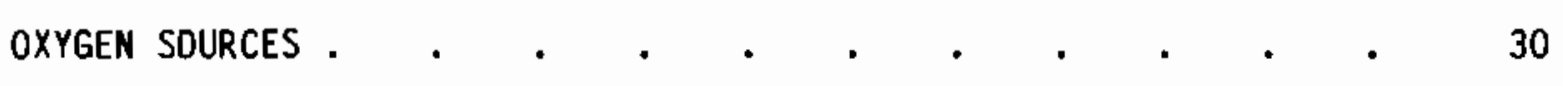

FUEL SOURCES •

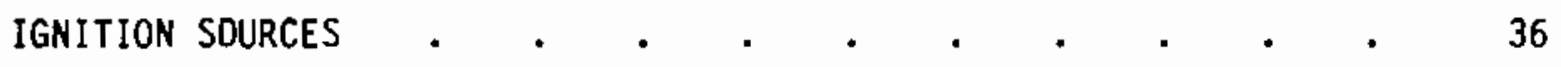

DESIGN BASIS ACCIDENT.$\quad \cdot \quad \cdot \quad \cdot \quad \cdot \quad \cdot \quad \cdot \quad \cdot \quad 41$ 


\section{FIGURES}

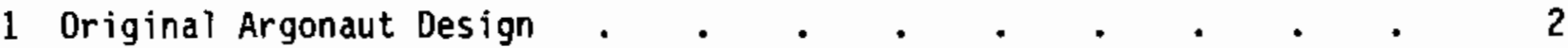

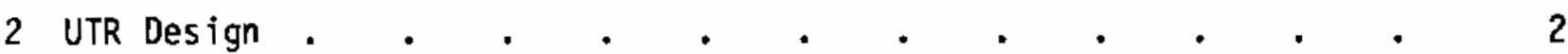

3 Feasible Fuel Loadings For Original Argonaut Design . . . . 10

4 Relative Power Densities of Normal Lattice. Transverse (A) and Longitudinal (B) Plot of Power Densities Through Horizontal Midplane

\section{TABLES}

1 Argonaut-UTR Reactors in the United States, 1980 . $\quad$ - . $\quad 3$

2 Net Percent Reactivities Available for Various Fuel

Box Arrangements . . . . . . . . . . .

3 Gaseous Fission Products in the Argonaut-UTR Element Containing the Greatest Activity Following Operation at $36.5 \mathrm{MWd}$

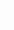

Activity and Dose Equivalents from Maximum Credible 


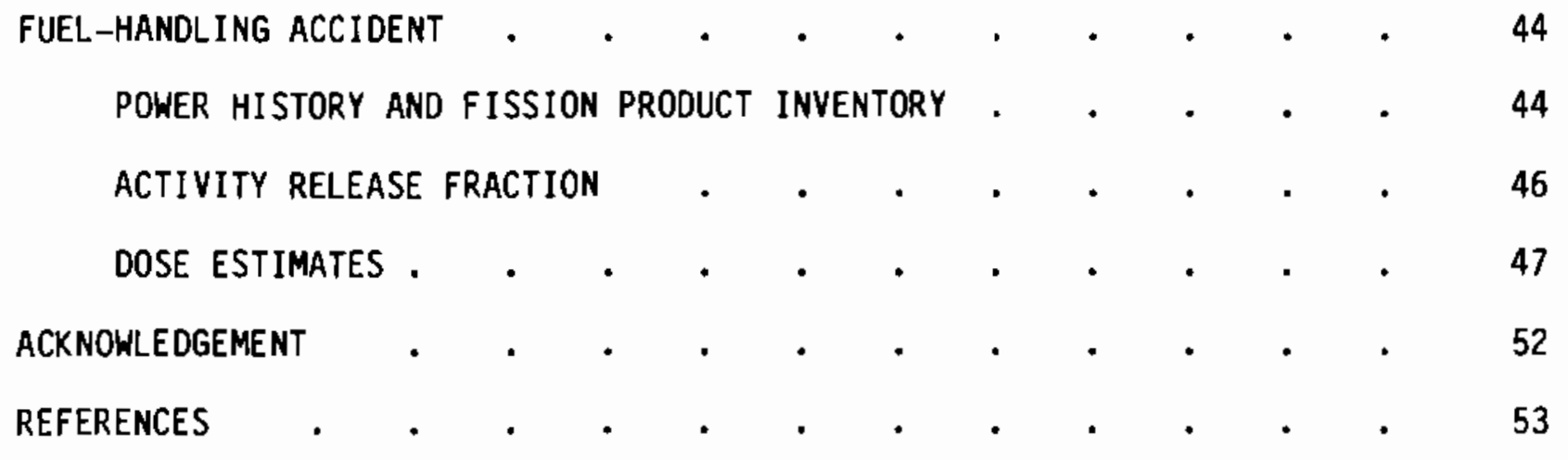





\section{INTRODUCTION}

A major objective in the early years of the Atomic Energy Commission was the development of an ultrasafe, low-power, training and research reactor for use by universities and other groups. During the early 1950s, Argonne National Laboratory (ANL) designed and constructed the prototype "Argonne naught" or Argonaut reactor, completing testing by the end of 1956 (Lennox and Kelber 1956).

The original design of the Argonaut (Figure 1) featured a graphitereflected, water-moderated annular core containing about $4 \mathrm{~kg}$ of ${ }^{235} \mathrm{U}$ in the form of $20 \%$ enriched plate-type fuel. Important fail-safe physics parameters, including relatively large negative void $(-0.25 \% \Delta \mathrm{k} / \mathrm{k}$ per $\%$ void $)$ and temperature $\left(-1.1 \times 10^{-4} \Delta \mathrm{k} / \mathrm{k}\right.$ per $\left.{ }^{\circ} \mathrm{C}\right)$ coefficients, were included in the design. The original reactor was capable of continuous operation at a thermal power of $1 \mathrm{~kW}$, with limited operation at $10 \mathrm{~kW}$. Sustained operation above about $1 \mathrm{~kW}$ would result in shutdown because of the negative temperature coefficient.

The American Machine and Foundry Company (AMF) manufactured the original Argonaut reactors. In the late 1950s, the American Radiator and Standard Sanitary Corporation (American-Standard) replaced AMF as the manufacturer of Argonaut-type reactors, producing a new design designated UTR-10 (University Training Reactor/10 kilowatts-see Figure 2). All five contemporary Argonauts in the United States (Table 1) are the UTR model and are capable of operation at power levels to $500 \mathrm{~kW}$, although none are currently licensed to operate beyond $100 \mathrm{~kW}$. The reactor at the University of California, Los Angeles (UCLA), has been operated at $500 \mathrm{~kW}$, but only on a temporary basis.

In addition to the five Argonaut-UTR reactors in the United States, 14 others, including both the original Argonaut and the UTR designs, are known to be operational in other countries.

Although various safety analyses have been performed, in general these were done for the original design Argonauts or for early UTRs and as such are based almost exclusively on limited experimental data. Hence the scope of these analyses is quite narrow. To expand and update these original studies, 


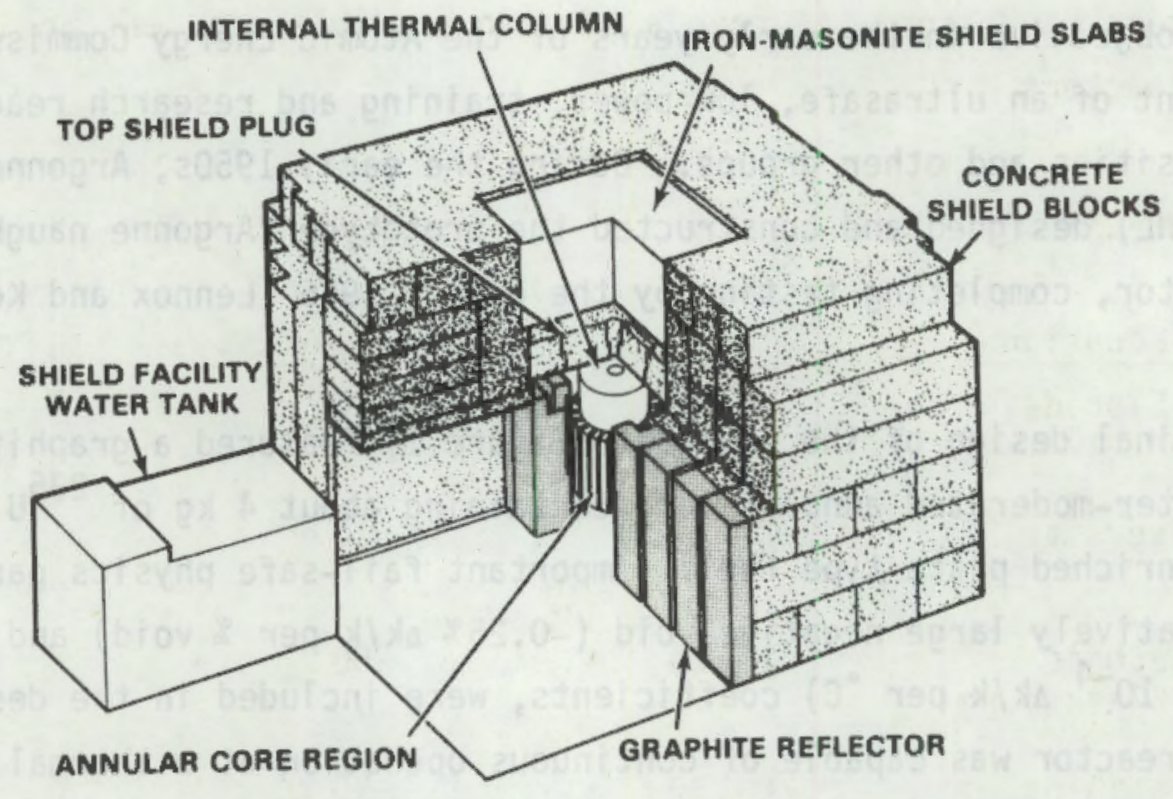

FIGURE 1. Original Argonaut Design

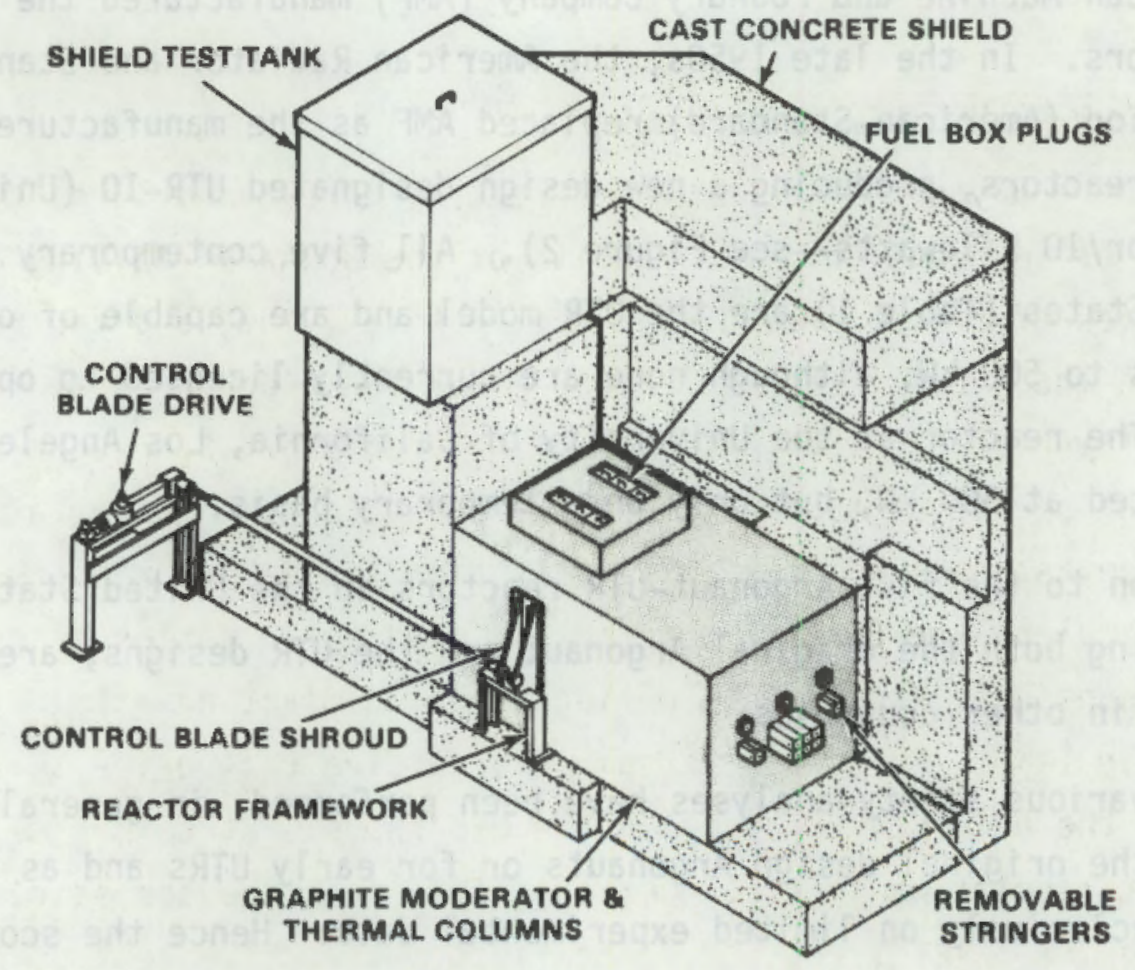

FIGURE 2. UTR Design 
particularly in the light of more than twenty years of operating experience and additional research, the Nuclear Regulatory Commission requested Battelle, Pacific Northwest Laboratory, to make a generic credible accident analysis of Argonaut-UTR reactors.

TABLE 1. Argonaut-UTR Reactors in the United States, 1980

\begin{tabular}{|c|c|c|c|}
\hline Licensee and Location & $\begin{array}{l}\text { Docket } \\
\text { Number }\end{array}$ & Enrichment, $\%$ & $\begin{array}{l}\text { Authorized } \\
\text { Power, kW }\end{array}$ \\
\hline $\begin{array}{l}\text { University of Florida, } \\
\text { Gainesville }\end{array}$ & $50-83$ & $90^{+}$ & 100 \\
\hline $\begin{array}{l}\text { Iowa State University, } \\
\text { Ames }\end{array}$ & $50-116$ & $90^{+}$ & 10 \\
\hline $\begin{array}{l}\text { Virginia Polytechnic } \\
\text { Institute, Blacksburg }\end{array}$ & $50-124$ & $90^{+}$ & 100 \\
\hline $\begin{array}{l}\text { University of Washington, } \\
\text { Seattle }\end{array}$ & $50-139$ & $90^{+}$ & 100 \\
\hline $\begin{array}{l}\text { University of California, } \\
\text { Los Angeles }\end{array}$ & $50-142$ & $90^{+}$ & 100 \\
\hline
\end{tabular}

\section{PAST HAZARDS ANALYSES OF THE ARGONAUT REACTOR}

Past hazards analyses of the Argonaut reactor were based largely on two primary sources of information: the results of the BORAX I (Boiling Reactor Experiment) series of tests, including a destructive event, and the results of initial tests on the SPERT I (Special Power Excursion Reactor Test) reactor (Dietrich 1955; Nyer et al. 1956; Edlund and Noderer 1957; Schroeder et al. 1957). The BORAX series of test reactors was operated by Argonne National Laboratory at the National Reactor Testing Station in Idaho during the early 1950s. In particular, the BORAX I reactor was used for a series of power excursion, or transient, experiments during 1953, culminating with a destructive test in July 1954. This was the only destructive test prior to the construction of the original Argonaut in the mid 1950s. At this time, only preliminary test results would have been available from the series of reactor transients using the SPERT I reactor. The first destructive test using the 
SPERT I configuration took place in November 1962. Two later SPERT I destructive tests were to use $4 \%$ enriched, stainless-steel-clad $\mathrm{UO}_{2}$ fuel, which is not applicable to the Argonaut.

The original Argonaut hazards analysis (Lennox and Kelber 1956) extensively referenced the data obtained from the BORAX I reactor experiments. The general Nuclear Engineering Corporation (GNEC) performed a hazards analysis on or before 0ctober 1958, which was used by at least three universities in their original Safety Analysis Reports (SARs) (Duncan 1958). Again, the BORAX I data predominated. A division of American-Standard, the Advanced Technology Laboratories (ATL), prepared a hazards summary for the UTR design in October 1959 and produced a later edition in 1961 (ATL 1959; Battles and Joki 1961). These two reports referenced only the preliminary SPERT I results, and the earlier of the two was extensively used in the preparation of at least one original SAR. The Safety Report for the Manchester and Liverpool Universities Research Reactor (URR) in England, also a UTR design, used SPERT I data in an analysis similar to the later ATL report (Manchester and Liverpool Universities 1966; Battles and Joki 1961). The only hazards analysis apparently available for a contemporary, original-design Argonaut reactor, the JASON reactor at the Royal Naval College (RNC), England, also extensively references the BORAX I and preliminary SPERT I data. (a)

Other than the two ATL reports, all of the hazards analyses made the following points regarding the original Argonaut:

- Since the excess reactivity is 1 imited to $\leq 0.6 \% \Delta k / k$, the reactor could never go prompt critical, and the heat capacity of the fuel plate would prevent the maximum energy release from raising the temperature of the fuel to its melting point.

- The reactor has negative temperature and void coefficients.

- The low maximum power (10 kW) would not produce large concentrations of fission products in the fuel plates.

(a) Personal communication from J. R. Lakey to R. L. Kathren, 1980. 
- Since a loss of coolant would be simultaneous with loss of moderation, the reactor would shut down upon loss of the core water, and even the decay heat from infinite operation at $10 \mathrm{~kW}$ would not be sufficient to melt the fuel.

Since none of these factors would allow melting of the fuel or cladding, there would be no credible way for the small amount of fission products in the core to escape; thus, all of the analyses concluded that the reactor was inherently safe. Note, however, that the value of excess reactivity given above was established as an operating limit, but the core excess is in fact greater--typically on the order of $1.5 \% \Delta k / k$.

In general the above are also applicable to the UTR modification, except that the UTR could accidentally go prompt critical and was designed for a maximum power of $100 \mathrm{~kW}$. However, it should be emphasized that the UTR design itself was also considered inherently safe.

Perhaps to demonstrate conclusively the safety of these reactors, and since data was available from the spectacular BORAX I destruction and some of the SPERT I tests, the original Argonaut safety analyses either determined the maximum amount of reactivity that could be inserted suddenly without causing fuel to melt or used the maximum available excess reactivity for a similar demonstration. Thus, the ANL study (Lennox and Kelber 1956) noted that a BORAX-type excursion would take place following a stepwise insertion of about $0.01 \% \Delta k / k$ into an Argonaut reactor, increasing in severity with increasing reactivity. Based on the BORAX I and SPERT I data, the Argonne team calculated that an instantaneous insertion of $4.75 \% \Delta k / k$ was necessary to initiate fue 1 plate melting, and concluded that the sequence of events (other than deliberate introduction of an appropriate quantity of fissile material) necessary to produce a stepwise insertion of this magnitude is simply not credible. Indeed, even in the event of failure of all control systems, the maximum available excess reactivity would have been on ly $0.5 \% \Delta k / k$.

The 1959 ATL analysis of the UTR design also stipulated a maximum available excess reactivity of only $0.5 \% \Delta \mathrm{k} / \mathrm{k}$ and used the SPERT I preliminary results to conclude that the fuel plates would not melt if all the available 
excess reactivity were to be suddenly inserted. Under this condition, the total energy release would be approximately 3 MWs (ATL 1959).

The later ATL analysis (1961) postulated a maximum $1.5 \% \Delta \mathrm{k} / \mathrm{k}$ reactivity addition. This was calculated to release 24 MWs of energy, creating a maximum fuel plate temperature of only $275^{\circ} \mathrm{C}$, which is well below the melting point of the fuel plates (Battles and Joki 1961).

The GNEC material (Duncan 1958) postulated a $1000^{\circ} \mathrm{F}\left(538^{\circ} \mathrm{C}\right.$ ) rise in fuel temperature, which, starting from nominal full-power operating conditions, would be sufficient to reach the melting point of aluminum $\left(660^{\circ} \mathrm{C}\right)$. A proportionality constant, in units of ${ }^{\circ} \mathrm{F} / \mathrm{MWs}$, was obtained from BORAX I data and multiplied by three ratios of values from the BORAX I and Argonaut reactors (void coefficients, peak to average power, and heat flux per degree of temperature difference). Applying the new constant to the $1000^{\circ} \mathrm{F}$ temperature rise produced the maximum allowable energy release of $32 \mathrm{MWs}$. A period of $0.007 \mathrm{~s}$ associated with the energy release was also obtained from a plot of BORAX I data. The amount of excess reactivity required to produce that period was reported as $2.4 \% \Delta k / k$, and it was stated that the reactor would tolerate this amount, rapidly inserted, without the fuel or cladding melting.

The Manchester and Liverpool URR Safety Report stated that a sudden reactivity insertion of $4.5 \% \Delta k / k$ would not release enough energy, i.e. about 15 MWs; for the cladding to reach $660^{\circ} \mathrm{C}$ (Manchester and Liverpool Universities 1966).

The JASON reactor at RNC has the same basic design as the ANL Argonaut. (a) The RNC accident analysis states that the maximum tolerable amount of reactivity that could be added stepwise is $2.4 \% \Delta \mathrm{k} / \mathrm{k}$, based upon a detailed analysis of BORAX I data. Depending upon core loading (either a single slab or an annulus), an energy release of 6.0 to $12 \mathrm{MWs}$ would raise the temperature of the hottest fuel plate to its melting point, provided there was no heat loss to the moderator. However, RNC also notes another calculation showing a total energy release of $10 \mathrm{MWs}$ from the stepwise addition of $0.5 \% \Delta \mathrm{k} / \mathrm{k}$ reactivity. The

(a) Personal communication from J. R. Lakey to R. L. Kathren, 1980. 
statements that a $2.4 \%$ reactivity addition will not produce more than 6.0 to 12 MWs and a $0.5 \%$ addition will produce 10 MWs are not resolved in the available JASON documentation. (a)

The sudden addition of large amounts of positive reactivity was regarded as the maximum credible accident in all the original Argonaut or UTR hazards analyses, perhaps because of the philosophy that initiated the BORAX and SPERT programs. All of the analyses examined this event, and each report concluded that the reactors concerned, as constructed and loaded, were immune from the phenomenon that destroyed the BORAX I core.

Several other potential accidents were examined by the early safety anaiyses, but none other than deliberate destruction of the core, were considered significant. The ANL group did explore the $\mathrm{A}\}-\mathrm{H}_{2} \mathrm{O}$ reaction, since it can release considerable energy, but limited their work because of the low probability that the conditions necessary for a blast would occur. However, this reaction is relevant in light of data from the SPERT I destructive test.

\section{NEEO FOR NEW HAZAROS ANALYSIS}

The original hazards analyses, now more than 20 years old, were largely empirical and were based on the relatively limited observations of the SPERT I and BORAX I experiments. While the conclusion that the UTR design is inherently safe from any severe consequences of a large sudden reactivity insertion may still be valid, it should be developed from a systemic analysis rather than from relatively broad extrapolation of limited empirical data. The scope of the analysis should also be extended to include consideration of other credible accident situations.

Specifically, there are five reasons why a new hazards analys is is needed:

1. At least four of the five currently licensed reactors have been significantly modified (either operationally or functionally), and the early changes from the Argonaut to the UTR design are not explicitly accounted for in the old hazards analyses.

(a) Personal communication from J. R. Lakey to R. L. Kathren, 1980. 
2. The SPERT I destructive test results are now available.

3. Values of measured parameters, such as prompt neutron lifetime and reactivity coefficients, are now available, in addition to the current reactors' operating histories.

4. More data on the release of fission products have been produced by experiments on melting samples of irradiated fuel and through other destructive tests.

5. The inadvertent transient may not be the maximum credible accident.

Because more recent and extensive data are now available, along with current values for parameters like prompt neutron lifetimes and reactivity coefficients, and because the comparisons that were used in prior analyses were somewhat vague, a new, more comprehensive analysis needs to be done to find out whether the UTR cores are immune from the serious consequences of an inadvertent pulse with the maximum available excess reactivity. An a priori calculation of the expected temperature rise from the largest possible pulse needs to be performed and the results compared with the data from the SPERT and BORAX experiments rather than relying solely on empirical extrapolations and interpolations of the same data.

This study, therefore, focused on these and other postulated generic accidents, including explosive chemical reactions, graphite fires, and fuel handling accidents. Deliberate destruction or similar events - i.e. sabotage was not considered in this study. Although the possible effects of major mechanical disturbances and shock waves were considered, the detailed aspects of these phenomena were not fully evaluated. Hence, in a future study, the potential severity of the shock wave phenomenon should be investigated for contemporary UTRs. The magnitude of the shock wave that the largest possible pulse is capable of generating and the largest shock wave the core can accommodate without fuel plate damage should be ascertained, although this task is beyond the scope of the present study. Conceivably, analys is of this problem could include the experimental measurement and evaluation of shock wave phenomena. 


\section{ACCIDENT POTENTIAL}

BASIC ARGONAUT DESIGN AND OPERATING CHARACTERISTICS

The ANL-designed Argonaut core (Lennox and Kelber 1956) had two concentric annuli of spaces for fuel elements. Each element contained approximately 10 plates of aluminum-clad, $20 \%$ enriched fuel, for a total of about $3.6 \mathrm{~kg}$ of ${ }^{235} \mathrm{U}$ in the core. The fuel meat was either an uranium-aluminum alloy or $\mathrm{UO}_{2}$ particles in an extruded aluminum matrix. Users had the option of choosing whatever arrangement of fuel elements best met their needs at any given time (Figure 3). The ANL hazards analys is considered a symmetrical loading of two arcs, a configuration that seems to have been used extensively. Various types of control devices were evaluated, but the final choice was a sheet of cadmium affixed to a flat steel spring that could be wound up out of the fuel region.

In the UTR design, two parallel slabs replaced the two symmetrical arcs (see Figure 2), with the spacing between the slabs approximately equal to onehalf the arc spacing. Instead of a common annulus, each group of four elements was contained in a fuel box. As far as is known, alloy fuel plates predominated. Cadmium remained as the neutron absorber material but was used in semaphore-type blades on both sides of the central fuel boxes. Each of the six separate fuel boxes had individual water inlets and outlets. In some cases, $90^{+} \%$ enriched uranium fuel was used for the first loading. All UTRs were licensed for a maximum initial power of $10 \mathrm{~kW}$, and most were increased to a 100-kW maximum power level after several years of operation.

The Argonaut-UTR reactors are characterized by large negative temperature and void coefficients and a relatively long prompt neutron lifetime. Typical values for these three nuclear parameters are $-1.1 \times 10^{-4} \% \Delta \mathrm{k} / \mathrm{k}$ per ${ }^{\circ} \mathrm{C}$; $-0.20 \% \Delta k / k$ per $\%$ void; and $1.9 \times 10^{-4} \mathrm{~s}$. The long prompt neutron lifetime, largely a function of the graphite reflection, requires that a greater amount of reactivity be inserted to achieve a given rate of power rise, or reactor period. 


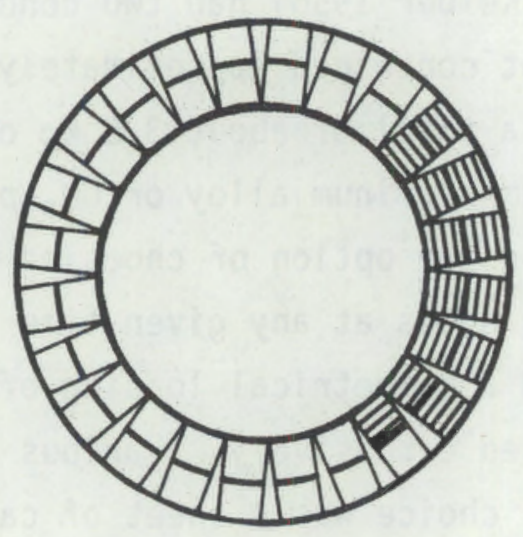

One-Sided Loading

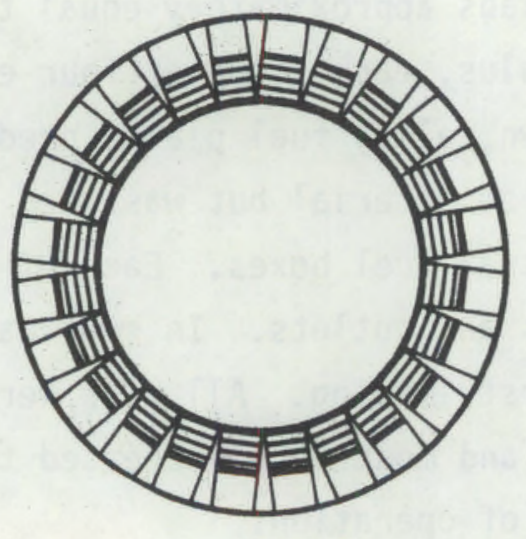

3-Inch Annular Loading

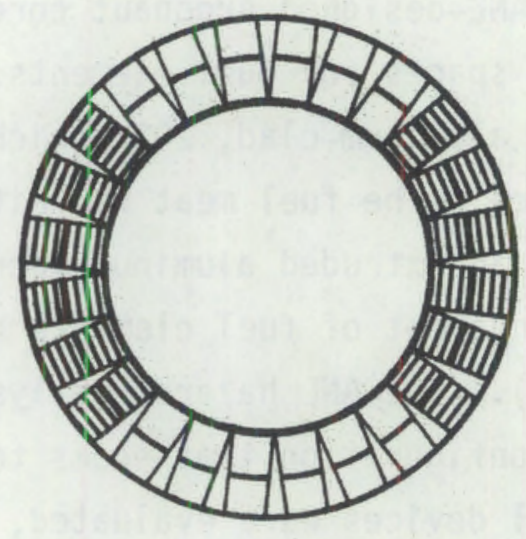

Two-Sided Loading

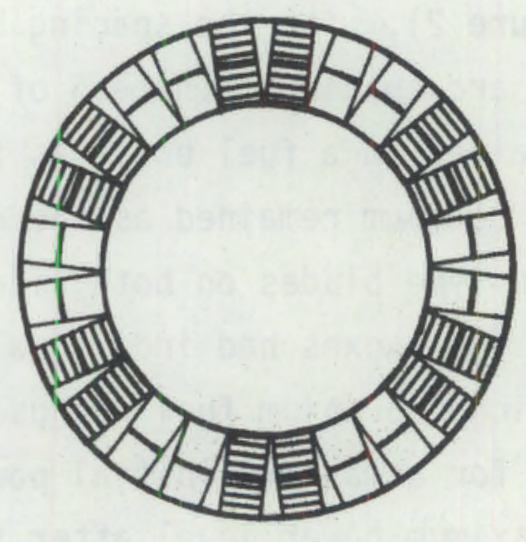

Two-By-Six Loading

FIGURE 3. Feasible Fuel Loadings for Original Argonaut Design 
Loss of coolant would drive the reactor subcritical, not only by creating large voids with a consequent rise in fuel temperature, but also because the moderator would be lost, since the water acts as both coolant and moderator. The reactivity worth of the core water is approximately $17 \% \Delta k / k$.

In general, mechanical rearrangements or core deformations produce negative reactivity. However, fuel plate spacing is an important determinant of the critical mass. The normal plate spacing of $0.3 \mathrm{~cm}(1 / 8 \mathrm{in}$.) results in a critical mass of about $3.6 \mathrm{~kg}$; increasing the plate spacing to $0.6 \mathrm{~cm}(1 / 4 \mathrm{in}$.) reduces the critical mass to $2.2 \mathrm{~kg}$, which is probably at or near minimum for the Argonaut reactor. The minimum value for critical mass is based on data obtained from slab-loading experiments (Lennox and Kelber 1956).

\section{DEVELOPMENT OF REALISTIC ACCIDENT SEQUENCES}

The early analyses of the Argonaut and UTR reactors provide a convenient starting place for the development of realistic accident sequences. In general, these analyses assumed that a rapid or stepwise insertion of reactivity would lead to maximum credible accident. However, since these early analyses did not have the benefit of the later SPERT I data, this potential accident should be re-examined in the light of more recently developed knowledge. Prior analyses stated that the Argonaut and UTR designs are inherently safe by virtue of selfshutdown mechanisms, which would act to terminate or dampen the power rise produced from large, essentially instantaneous reactivity insertions. The energy release from the power excursions would consequently be limited so that the fuel cladding would not melt. The earlier analyses identified the maximum amounts of reactivity that could be inserted without causing melting of the cladding and, implicitiy, without causing severe disruption of the core. The complete series of the SPERT I studies determined the rates of power rise, or reactor periods, at which fuel or cladding melting first appeared and at which widespread melting was also accompanied by a destructive pressure increase or shock wave.

The SPERT and BORAX studies identified the reactor period as the fundamental variable controlling the magnitude of temperature rise from a pulse or transient. The maximum power level and consequentiy the total energy 
release are a function of the period. For a pulse, the magnitude of the period is determined by both the amount of reactivity instanteously inserted beyond prompt criticality, and the prompt neutron lifetime, which is a function of the moderator and reflector for a given core configuration. The temperature rise in the fuel plates is a function of the total energy release, the heat capacities of fuel and coolant, and the amount of heat transfer from fuel to coolant. The tremendous physical core disruption from the SPERT I destructive test was caused by a shock wave that occurred after the nuclear excursion had decreased to a very low power (Miller, Sola and McCardell 1964). It is also thought, upon re-examination of BORAX I films, that a shock wave was responsible for its disruption also (Russel1 1962).

Re-evaluation of potential inadvertent transients should produce results similar to those already attained. Escape of fission products from fuel to gap or gap to environment might occur in other ways or in a combination of ways. Since amounts of explosives permitted for irradiation purposes are usually limited to a few milligrams, a conventional type of explosion will not be anong the ways considered to release fission products. While comonplace substances may not always be recognized by an individual as having explosive capabilities, (e.g., ammonium nitrate), both the required review system for experiments at research reactors and the small quantities usually involved in irradiations preclude a severe inadvertent chenical explosion.

Natural disasters, such as earthquakes or tornadoes, could cause mechanical rearrangement of the fuel boxes, which might lead to or contribute to fission product release from mechanical damage or through creation of an inadvertent supercritical lattice. Secondary effects, such as fire or flooding, could cause additional fission product release.

However, the metal-water chemical reaction, which, according to postincident surveys, occurred sometime during the SPERT I and SL-1 destructive excursions, has the potential to occur in the UTR reactors (General Electric Company 1962; Miller, Sola and McCardell 1964; Baker and Liimatakinen 1973). As the prior analyses and experimental work indicate, the $\mathrm{Al}-\mathrm{H}_{2} \mathrm{O}$ reaction happened after, or as a result of, the combination of heat generated by the 
nuclear excursion and the dispersal of molten aluminum by the shock wave. This chemical reaction is not generally considered as initiating a destructive event, but rather an additional problem occurring at the end of the destructive event, as the reaction needs considerable energy input in order to release additional energy; i.e., the aluminum has to be molten or finely divided before the exothermic reaction occurs. Thus, this reaction only needs to be considered if any one of the credible accidents creates an energy release sufficient to melt the fuel and produce a shock wave. It would contribute to the overall severity of the incident primarily by increasing the amount of fission products released, not necessarily by creating additional physical damage, since any event that initiated the $\mathrm{Al}-\mathrm{H}_{2} \mathrm{O}$ reaction would be so severe that the amount of physical damage caused by the chemical reaction would be minor by comparison.

Chemical reactions that cause dissolution of the cladding and fuel would also allow escape of fission products. A relatively long-term dissolution process would have effects similar to those of corrosion, either through the inadvertent addition of chemicals to the coolant/moderator system or through faulty water maintenance procedures. It is conceivable that substances could be deliberately added to cause rapid dissolution of the fuel plates, but as noted above, sabotage is beyond the scope of this report.

The chemical combination of graphite and oxygen--a graphite fire--could release enough heat to cause fuel melting and possibly a release of fission products. Several mechanisms could lead to a graphite fire, such as apparatus or human error as well as the wigner effect. If any of these possibilities were to occur when there was no coolant in the core, the potential of a graphite fire would be even greater. Moreover, the water used to extinguish a fire could lead to steam or other explosive reactions, including the $\mathrm{Al}-\mathrm{H}_{2} \mathrm{O}$ reaction. Even cooling of the fire, if sufficiently rapid, might lead to contraction and flexing of metallic components that might rupture the cladding and lead to fission product release.

It is conceivable that a fuel element could accidentally be dropped or otherwise damaged during a fuel-handling process. The minimum damage required to create a radiological hazard would be a breach of the cladding, and further damage would be created by tension or compression forces that could crack or 
break the fuel meat, thus exposing more fuel surface area to the environment. Since the fuel element would be in air, minimally shielded and although probably handled remotely, near onsite personnel, the containment features are reduced to a minimum thereby creating the hazard from an accident of this type.

In summary, five areas of potential credible accidents bear analys is:

- rapid or stepwise insertion of reactivity

- mechanical rearrangement of the core, as from a natural cataclysmic event, such as an earthquake

- chenical explosion (i.e., metal-water reaction)

- graphite fire

- fuel-handiing accident

These accidents and the potential consequences of each will be examined below. 


\section{EXCESS REACTIVITY ACCIDENTS}

An inadvertent pulse or power spike is the consequence of a stepwise or rapid insertion of positive reactivity. Many mechanisms might provide this sudden excess reactivity, including the addition of a source of reactivity other than that available from the reactor itself. This section will consider the credibility and consequences of a sudden insertion of reactivity into a reactor that is operating in a normal steady-state mode.

\section{MAXIMUM EXCESS REACTIVITY}

The five UTR reactors currently licensed in the United States are limited to a maximum excess reactivity of $2.3 \% \Delta k / k$. Since the rate of fuel consumption is small and the maximum xenon concentration is also small, all of the excess reactivity should be available when the reactor is at normal operating temperature $\left(\sim 60^{\circ} \mathrm{C}\right)$. Measurements of excess reactivity, assumed to be precise and accurate to within $\pm 1 \%$, are made when the reactor is at nomal operating temperatures, although still at low power. If the coolant/moderator is at $4^{\circ} \mathrm{C}$, the temperature of maximum density for water, the excess reactivity will be increased to $2.6 \%$, an increase of $0.3 \%$, obtained from the averaged value of reported temperature coefficients for four of the Argonaut-UTR reactors (UCLA 1980; Virginia Polytechnic Institute and State University (VPI) 1979). For purposes of this safety analysis, the conservative value of $2.6 \%$ excess reactivity will be used, which requires only that the coolant/moderator be at lower than normal operating temperature. This is not unlikely, since winter temperatures could conceivably cool the stored moderator or cool water could be added from the basins. Similarly, since the fuel temperature coefficient of reactivity is very small, the initial fuel temperature will be assumed to be the sane as the nominal operating temperature $\left(60^{\circ} \mathrm{C}\right)$; although, if the coolant/moderator is at $4^{\circ} \mathrm{C}$, there would be significant heat flow and a measurable drop in the fuel temperature.

Except by deliberate additions of positive reactivity (i.e., fuel) or rearrangement of the core, there is virtually no likelihood of obtaining an excess reactivity greater than $2.6 \% \Delta k / k$. Any experiments nomally done would 
have the net effect of reducing the available excess. In rare cases, some uranium might be inserted into the central thimble; the resulting addition would not exceed a few cents of reactivity, if that. Consider, for example, the addition of $100 \mathrm{~g}$ of ${ }^{N a t} \mathrm{U}$ to the central thimble; this amounts to $0.7 \mathrm{~g}$ of ${ }^{235} \mathrm{U}$, for an estimated increase of about $0.003 \% \mathrm{\Delta k} / \mathrm{k}$, taking into account the thermal capture by the ${ }^{238} \mathrm{U}$. This increase is trivial.

A conceivable addition of reactivity could result from a change in the moderator. In the Argonaut-UTR, the moderator worth is about $17 \% \Delta \mathrm{k} / \mathrm{k}$. Any reduction of the moderator (e.g., by draining from the core or formation of voids) actually reduces the reactivity of the system. If the light water used as coolant and moderator were replaced by a superior moderator, then the reactivity of the reactor system would be increased. Heavy water has a greater moderating ratio than light water and may or may not be a superior moderator in the Argonaut-UTR geometry. In any case, the substitution of heavy water is not credible. This same conclusion applies to pressurized helium or organic compounds with moderating ratios greater than that of light water. Although possible, accidental replacement of all or an appreciable portion of the light coolant/moderator with a superior moderator is not a credible or feasible accident scenario.

MAXIMUM ENERGY RELEASE

As mentioned earlier, the maximum energy release is a function of the asymptotic (i.e., prompt) period, $T$, in seconds, which can be readily calculated from the following form of the inhour equation:

$$
T=\frac{\ell}{\left.\Delta k / k\left(1-B_{e f f}\right)-\beta_{e f f}\right]}
$$

where: $\quad l$ is the mean prompt neutron lifetime, in seconds

$\Delta k / k$ is the available excess reactivity

${ }^{B}$ eff is the effective fraction of delayed neutrons.

From Paragraph $4.2, \Delta k / k$ has a maximum value of $2.6 \%$. Values for $\ell$ are available in the literature and range from 0.14 to $0.28 \mathrm{~ms}$ (VPI 1979; University of Florida 1980). The fraction of delayed neutrons, Beff, is dependent upon 
the type of fuel used; the most conservative value (the one that produces the shortest prompt period) is 0.0065 , found for thermal fission of pure (or very highly enriched) ${ }^{235} \mathrm{U}$. Putting the conservative values of $1.4 \times 10^{-4} \mathrm{~s}$ and 0.0065 into Equation (1) yields a calculated period of:

$$
T=\frac{1.4 \times 10^{-4}}{[0.026(1-0.0065)-0.0065]}=7.2 \times 10^{-3} \mathrm{~s}
$$

and a reciprocal period, $a$, of $138 \mathrm{~s}^{-1}$. As noted, this calculated value is quite conservative.

Given the reciprocal period, $a$, and a reactivity coefficient, $b$, in units of $s^{-1} /$ MWs, the total energy release is easily found, assuming a symmetrical power increase and decrease, by the relation:

$$
E_{\text {total }}=2 a / b
$$

The reactivity coefficient is a measure of how much energy a given reactor can safety accommodate, and implicitly takes into account the shutdown mechanisms that terminate the power rise. The value of $b$ varies with the amount of energy (expressed as reciprocal period) produced. Using a plot of reciprocal period versus energy release to peak power, obtained from the SPERT I destructive test (Miller, Sola and McCardell 1964), the coefficient for $138 \mathrm{~s}^{-1}$ is found to be about $23 \mathrm{sec}^{-1} / \mathrm{MWs}$, for a total energy release of $12 \mathrm{MWs}$.

The maximum or total energy release can also be determined empirically using the equation

$$
E_{\text {total }}=\frac{2 P_{\max }}{a}
$$

where $P_{\max }$ is the maximum power. This equation assumes a symetrical power burst and is therefore conservative, since more energy is released in the early part of the burst than subsequentiy (Milier, Sola and McCardell 1964). The maximum power, $P_{\text {max }}$, in MW, can be determined from the following empirically derived relationship obtained from the SPERT I destructive test (Miller, Sola and McCardell 1964).

$$
P_{\max }=0.13 a^{1.72}
$$


Then, combining Equations (3) and (4),

$$
E_{\text {total }}=0.26 \alpha^{0.72}
$$

For $a=138 \mathrm{~s}^{-1}$, corresponding to the maximum available excess reactivity insertion, $E_{\text {total }}$ can then be calculated as: $E_{\text {total }}=0.26(138)^{0.72}=$ 9.0 MWs, which is in good agreement with the 12 MWs value obtained above.

Based on the above, the maximum energy release, using conservative values, would be no greater than $12 \mathrm{MWs}$. This corresponds to a criticality spike of about $4 \times 10^{17}$ fissions. In perspective, this calculated maximum energy release for an Argonaut-UTR accident is about in the midrange of the spectrum of observed contemporary criticality accidents (Thompson 1964) and is not large enough to produce core disruption leading to cladding failure.

\section{FUEL PLATE HEAT CAPACITY AND TEMPERATURE RISE}

The heat capacity of the fuel can be calculated using Dulong and Petit's rule, which states that the molar heat capacity of a solid has a nearly constant value of $6 \mathrm{cal} / \mathrm{mole}-{ }^{\circ} \mathrm{C}$ or $2.54 \times 10^{-5} \mathrm{MWs} / \mathrm{mole}-{ }^{\circ} \mathrm{C}$. Taking the cold clean critical mass of the Argonaut-UTR core as $3.6 \mathrm{~kg}{ }^{235} \mathrm{U}$ with $13 \mathrm{wt} \% \mathrm{U}$ gives 1846 moles total, for both fuel and cladding. The capacity of the fuel is therefore $1846 \times 2.54 \times 10^{-5}=0.05 \mathrm{MWs} /{ }^{\circ} \mathrm{C}$ (or a temperature coefficient of $22^{\circ} \mathrm{C} / \mathrm{MW}$ ) neglecting the slight increase in heat capacity that would occur with increasing temperature. Hence, the adiabatic temperature rise of the fue 1 plate would be $240^{\circ} \mathrm{C}$ for a 12-Mws burst, assuming uniform heating of the fuel, yielding a final temperature of $300^{\circ} \mathrm{C}$, given an initial fuel temperature of $60^{\circ} \mathrm{C}$.

The typical UTR fuel containing 13.4 wt\% $U$ has a composition very close to the AT-U eutectic alloy of 13 wto $U$, which melts at $640^{\circ} \mathrm{C}$ (Elliot 1965; Saller 1956). Thus, given an initial fuel temperature of $60^{\circ} \mathrm{C}$, the permissible temperature rise would be $580^{\circ} \mathrm{C}$ before melting would be expected to occur. If the volume increase the fuel melt undergoes upon melting is the initial or primary cause of rupture of the fuel plate cladding and the consequent release of fission products, then it is important that alloys at or close to the eutectic have an adequate margin of safety with regard to temperature. 
Again, comparison can be made with the SPERT I fuels, which are also plate type and $93 \%$ enriched, but which contain 24 wt\% of uranium (Miller, Sola and McCardel1 1964). Melting in these fuels should appear at $640^{\circ} \mathrm{C}$. However, molten fuel eruptions were noted when the temperature of the fuel plate surface was as low as $590^{\circ} \mathrm{C}$, demonstrating the existence of hot spots within the fuel (Miller, Sola and McCardell 1964). The hot spots may result from inhomogeneities in the fuel or, more likely, from the reduced cooling that would occur under steam bubbles or film boiling. The SPERT I destructive test produced an excursion of some $30.7 \mathrm{MWs}$, or roughly 2.5 times the maximum energy release postulated for the Argonaut-UTR maximum credible accident, and yielding an estimated peak temperature of $1500^{\circ} \mathrm{C}$. Assuming linear scaling of temperature and energy release, this suggests a peak temperature or hot spot within the UTR core to be $586^{\circ} \mathrm{C}$ or about $74^{\circ} \mathrm{C}$ below the melting point of the fuel meat. Hence, neither melting nor an associated volume change leading to cladding failure is credible, since the peak temperature rise is well below the eutectic temperature and the $74^{\circ} \mathrm{C}$ margin of safety is certainly adequate, especially in light of the highly conservative assumptions on which the calculation was based. More realistic values of prompt neutron lifetime, as deduced from the literature, are on the order of $2 \times 10^{-4} \mathrm{~s}$. This value yields a peak energy output of less than 10 MWs, and results in a calculated adiabatic peak cladding temperature slightly below $500^{\circ} \mathrm{C}$, allowing a rather large $170^{\circ} \mathrm{C}$ margin of safety.

Peak fuel-cladding temperatures can also be simply estimated by taking the ratio of peak to average energy release, power density, or flux and some fraction of the core as the region where the greatest value occurs. A typical peak-to-average flux ratio is on the order of 1.5 or less for Argonaut-UTR reactors (Battles and Joki 1961; University of Florida 1980). This value is conservative, i.e., greater than the calculated values (Figure 4) of power density as discussed in the next section of this report. In the UTR design, the centermost fuel plates, which make up one-sixth of the total core, are in the region in which the greatest energy release occurs. Therefore, one-fourth of the total energy of the Argonaut-UTR maximum credible accident, or 3.0 MWs, would be released in 40 fuel plates, or $0.075 \mathrm{MWs} /$ fuel plate, well below the level of 0.156 MWs/fuel plate established for the SPERT I fuel (Ivins 1963). 


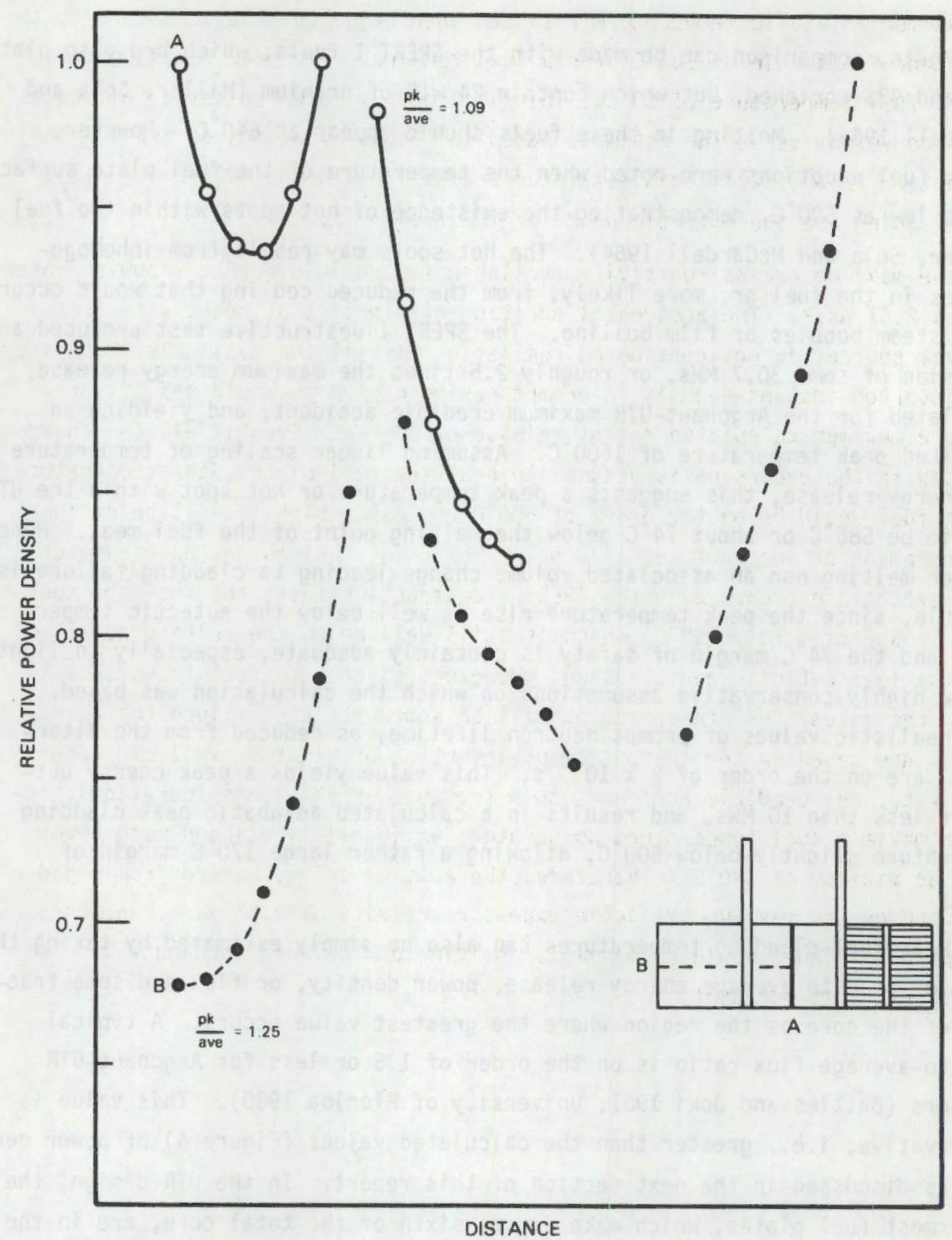

FIGURE 4. Relative Power Densities of Normal Lattice. Transverse (A) and longitudinal (B) plot of power densities through horizontal midplane. Quarter core symmetry assumed. Alternate fuel plates plotted for $\mathrm{A}$; three plates for $\mathrm{B}$. 
The maximum adiabatic temperature rise can then be calculated according to the Dulong and Petit rule as $388^{\circ} \mathrm{C}$, for a fuel temperature of $448^{\circ} \mathrm{C}$, assuming an initial fuel temperature of $60^{\circ} \mathrm{C}$. This is probably more realistic, although not as conservative as the estimate based on the observations of SPERT I fuel hot spots. In any case, both estimates are well below the melting point of the fuel cladding and the eutectic point of the fuel meat.

The maximum excess reactivity available for an inadvertent stepwise insertion is $2.6 \% \Delta \mathrm{k} / \mathrm{k}$. The accidental addition of significant reactivity from external sources is not considered realistic. If all the available reactivity were inserted instantaneousiy, a prompt period of 7.2 ms would result, producing a maximum calculated energy release of $12 \mathrm{MWs}$. Even if all the energy released in the excursion is assumed to heat the fuel plates, the temperature of the fuel would be on the order of $500^{\circ} \mathrm{C}$ or less, which is well below the melting point of the fuel eutectic or the cladding. Based on the estimated peak temperature produced in the SPERT I destructive test, the fue 1 hot spot would be approximately $590^{\circ} \mathrm{C}$, which is still well below the meiting points of both the fuel eutectic and cladding. However, since some heat transfer will occur, the actual fuel temperatures will be somewhat less. Since the above results are based on the instantaneous insertion of all the available excess reactivity, any credible accident would (because of its longer duration) produce a maximum fuel temperature no greater, an in all likelihood much lower, than the maximum of $590^{\circ} \mathrm{C}$. Therefore, there is no safety hazard from rapid insertion of the maximum available excess reactivity of $2.6 \% \Delta \mathrm{k} / \mathrm{k}$, and core disruption, if any, would be minimal. Melting of fuel or cladding would not result from this accident. 


\section{CATASTROPHIC MECHANICAL REARRANGEMENT OR FLOODING}

The energy potentially available from a severe natural catastrophe, such as a major earthquake or other ground subsidence, a tornado, or a volcanic eruption, could produce a mechanical shifting or rearrangement of the core that would result in a reduced minimum critical mass. The rearranged lattice, if moderation were not lost as a result of the core disruption, might become supercritical, producing additional energy and increasing the fission product inventory. If fuel integrity were breached, as might result from the tension and compression forces associated with the catastrophic event, a release of activity might occur.

Unfortunately, the design loadings and related engineering data for the existing Argonaut-UTR reactors are site specific and not generally available. Hence, it is not known whether the reactors meet General Design Criterion 2 of Title 10, Part 50, Appendix A, of the U.S. Code of Federal Regulations (10 CFR 50). Examination of the existing safety analysis reports suggests that the effects of catastrophic seismic phenomena have been addressed in detail in only one case (UCLA 1980).

However, only four basic categories of accidents could result from a severe natural phenomenon such as an earthquake:

- flooding

- mechanical rearrangement of the core, with flooding.

- mechanical rearrangement of the core, without flooding

- crushing or major torsional destruction of the core.

\section{FLOODING}

Flooding of the reactor with water could result from the rupture of a pipe or a water storage tank, or, although unlikely, from blockage of the drain line. Since the Argonaut-UTR is a light-water-moderated reactor in which the water is essential for operation, no significant effect would result from flooding unless structural rearrangement of the core also occurred or the control blades were somehow prevented from being inserted into the core. These situations are considered below. 


\section{URANIUM CRITICAL MASS}

The reported fuel requirement for a cold, clean UTR core is $3.2 \mathrm{~kg}$ of ${ }^{235} \mathrm{U}$ (UCLA 1980). The nominal fresh loading is $3.6 \mathrm{~kg}$. The criticai mass can be reduced to $1.9 \mathrm{~kg}$, producing a fuel excess of $1.7 \mathrm{~kg}$, by decreasing the slab spacing to zero and eliminating the control blade air slots (University of Washington 1960). A first approximation, using $6.5 \times 10^{-3} \% \Delta k / k$ per gram of fuel (Lennox and Kelber 1956), yields $11.1 \%$ excess reactivity if the fuel boxes were somehow brought together, which is essentially noncredible since to do so would require renoval of the central reflector island. Eliminating only the air slots would produce $6.5 \%$ excess reactivity, while keeping the air slots but bringing the two slabs together would produce $4.6 \%$ excess reactivity.

The normal spacing of fuel plates for the UTR design is $0.348 \mathrm{~cm} 10.137$ in.). The ANL study (Lennox and Kelber 1956) gives a plate spacing of 0.635 $\mathrm{cm}(0.250 \mathrm{in.})$ as producing the minimum fuel requirement of $2.2 \mathrm{~kg}$. Further increases in spacing between plates would again increase the fuel requirement.

This discussion assumes that some moderator, i.e., water, is present in the core. In a dry core, the minimum critical mass is increased despite a change to a more compact geometry. Were there no moderation or reflection, the minimum critical mass would approach $22.8 \mathrm{~kg}$. However, the graphite reflector is still present in a dry reactor. Given the situation in which the core is collapsed into a compact configuration with near total or even total reflection, the minimum critical mass would still exceed the $3.6 \mathrm{~kg}$ of fuel in the core. Even with the optimum ratio of fuel to moderator, a reactor fueled with $235 \mathrm{U}$ and homogeneously moderated with graphite requires approximately $7 \mathrm{~kg}$ of fuel (Harper 1961), or about twice the quantity in a freshly loaded core.

STRUCTURAL REARRANGEMENT AND FLOODING

The most compact geometry of the fuel box creates the most excess reactivity but would require the most severe structural rearrangenent. To produce even partial compaction of the fuel boxes would require that forces acting randomly either dislodge the solidly packed graphite from between the slabs and create precise alignments of the fuel boxes or act only when the control blades 
are fully withdrawn or cause them to withdraw and then squeeze the slots together or otherwise eliminate the spacing afforded by the control blade slots.

As noted above, reduction of the fuel plate spacing increases the minimum critical mass-i.e. decreases the reactivity. An effective increase in spacing resulting in a reduction of minimum critical mass, while possible, is so unlikely as to be noncredible, since the necessary forces would result in partial collapse or compression of the spacing in other areas with a concomitant offsetting increase in minimum critical mass. Since the plates are locked in a rigid geometry, it is unlikely that significant spacing changes will occur. Indeed, geometric deformation will very likely effectively reduce interplate spacing. Hence, for conservatism, the normal plate spacing was assumed.

The UTR typically has several air-filled voids in its structure that could become flooded in the event of a major structural rearrangement from an earthquake or similar mechanical shock. Thus, the volumes around the control blades (or the entire volume occupied by the blades if these are in the out-of-core position), the beam ports, and the interstitial spaces within the graphite could become flooded, producing a net positive change in reactivity. Although water in the interstitial graphite spaces is known to decrease reactivity, this decrease would be more than offset by the increase from the other flooded voids.

Based on a typical UTR void coefficient of $0.2 \% \Delta \mathrm{k} / \mathrm{k}$ per $\%$ void, the control blade spaces would create $2 \% \Delta \mathrm{k} / \mathrm{k}$ if flooded. The negative reactivity generated by the interstitial water in the bulk moderator would be offset by the positive reactivity generated by the flooding of the experimental facilities and control blade slots. Thus, $2 \% \Delta k / k$ will be taken as the positive reactivity created by either severe flooding of the reactor or flooding the control blade spaces only.

Table 2 shows the theoretical net percent reactivities generated by the postulated rearrangements, with the parameters of no water in the fuel boxes, normal water level, and flooded control blade spaces. The net reactivities were calculated assuming a $2.6 \% \Delta \mathrm{k} / \mathrm{k}$ core excess, typical reported values for total blade worth $(-5.8 \% \Delta \mathrm{k} / \mathrm{k})$, and total loss of all of the core water $(-17 \%$ $\Delta k / k)$. 
TABLE 2. Net Percent Reactivities Available for Various Fuel Box Arrangements

\begin{tabular}{|c|c|c|c|c|c|c|}
\hline & $\begin{array}{c}\text { Nor } \\
\text { Configh } \\
\text { Blades } \\
\text { In } \\
\end{array}$ & $\begin{array}{l}\text { mal } \\
\text { ration } \\
\text { BTades } \\
\text { Out } \\
\end{array}$ & $\begin{array}{l}\text { Slabs } \\
\text { Blades } \\
\text { In } \\
\end{array}$ & $\begin{array}{l}\text { gether } \\
\text { Blades } \\
\text { Out }\end{array}$ & $\begin{array}{c}\text { Slots } \\
\text { Eliminated } \\
\text { Blades Out } \\
\end{array}$ & $\begin{array}{l}\text { Slabs Together } \\
\text { Slots El iminated } \\
\text { Blades Out }\end{array}$ \\
\hline No $\mathrm{H}_{2} \mathrm{O}$ & -20.2 & -14.4 & -15.6 & -9.8 & -7.9 & -3.3 \\
\hline Normal $\mathrm{H}_{2} \mathrm{O}$ & -3.2 & 2.6 & 1.4 & 7.2 & 9.1 & 13.7 \\
\hline $\begin{array}{c}\text { Flooded } \\
\text { Slots }\end{array}$ & -1.2 & 4.6 & 2.4 & 8.2 & N.A. (a) & N.A. \\
\hline
\end{tabular}

(a) Not applicable.

If flooding occurred during a major structural rearrangement that reduced the minimum critical mass, than a large amount of excess reactivity could result. As previously stated, the minimum critical mass is $1.9 \mathrm{~kg}$ of ${ }^{235} \mathrm{U}$. If the rearrangement produced the geometry for this minimum, the total reactivity of the core would be $13.7 \% \Delta k / k$, which requires that the control blades be fully withdrawn or otherwise ineffective. Such a configuration is considered incredible because a shock intense enough to produce the required extensive mechanical rearrangement would also shear water lines and create other paths for water to leak out of the core. Only if there were a secondary external water source for the core could this accident be considered potentially credible. Even in this extraordinarily unlikely case, the magnitude of the nuclear excursion would be approximately that of the situation discussed earlier, in which a cold, clean, dry core is flooded.

The creation or addition of these large reactivities would take place over a time long compared to the pulsing syndrome. In addition, the probability that any rearrangement would allow for the boxes or slabs to come into contact without concomitant loss of moderation is not credible and is therefore assumed to be insignificant. Thus, the most credible consequences of a severe natural disaster would be 1) flooding and 2) some damage to the fuel elements, due to mechanical rearrangement, sufficient to release some of the fission products. In the latter case, it is possible that an appreciable fraction of the fuel 
plates would be damaged and that fission product activity would get into the water. Detailed analysis of this accident and its consequences are beyond the scope of this study.

\section{CORE-CRUSHING ACC IDENT}

Fracturing of the ciadding and fuel meat would allow some fission products to escape from the fuel plates. One source of the compression or tension forces that could cause such darnage to the fuel wold be a massive object dropped on the unshieided assembly. The UTR uses large, cast-concrete blocks for shielding. These blocks must be removed to gain access to the fuel elements, as is required for a fuel unloading operation. This study postuiates that the heaviest block is removed last, thus creating maximum damage to the core if it should be dropped. At two facilities (University of Washington 1960; UCLA 1980), the weights of the heaviest blocks are identical with the crane capacity, stated as a 3- or 10-ton crane. While a dropping accident is credible given the crane capacities and the weights of the heaviest blocks, the shield assembly may require that the heaviest block be removed while the core is still structurally well-shielded. Thus, the heaviest block could not be dropped directly onto the core, since other shield blocks would protect against this possibility.

When any blocks are being moved, the reactor would be shut down and the severity of the fission product release would be lessened through decay of the short-lived gaseous fission products. The amounts of fission products released from irradiated unclad fuel at room temperature would be much smaller than the amounts released from molten fuel, and the actual amount of fission product release would be a function of the degree and exten: of damage to the fuel meat and cladding. A later section of this report, on a fuel-handling accident, develops the consequences of damage to a single fuel element. The similar consequences from a core-crushing accident would be sore multiple of the consequence of the fuel-handing accident. 
THEORETICAL VERIFICATION OF REACTIVITY CHANGES

Neutronics calculations were made to determine the increase in reactivity that would be produced from the following three abnormal situations, selected without regard to credibility:

1) flooding the air spaces normally present in the core

2) partial collapse of the lattice to form a more compact core

3) complete collapse of the lattice.

The NITAWL code (Greene et.al. 1976) was used to determine shielded resonance cross sections, and XSDRN (Greene and Craven 1960) was used to obtain the 27-group spectrum of a fuel plate plus associated cladding and water and to edit the cross sections to four groups. A two-dimensional diffusion theory code, 20B (Little and Hardie 1969), was used to model the reactor in the horizontal $(x-y)$ plane, using quarter-core symetry. Perpendicular leakage was accounted for by an assumed axial buckling of $1.66 \times 10^{-3} \mathrm{~cm}^{-2}$.

The calculated values for each of the three abnormal cases were compared with similar calculations done for a normal lattice. The results show the same trend as the estimates made in our analys is above. Flooding the core air spaces with the blades out was found to add $5.6 \% \Delta k / k$, compared with the $2 \%$ derived from the typical void coefficient. Partial collapse was calculated to increase reactivity by $8.7 \% \mathrm{\Delta k} / \mathrm{k}$ over a normal lattice, while complete collapse was calculated to produce an increase of $18.5 \% \Delta \mathrm{k} / \mathrm{k}$. Comparable values derived from Table 2 are 6.5 and $11.1 \% \Delta k / k$, respectively. The apparent significance of these differences is most likely attributable to the value assumed for the buckling. Use of an actual measured or derived buckling value for specific Argonaut-UTR geometries should eliminate the observed differences. 


\section{EXPLOSIVE CHEMICAL REACTIONS}

The chemical reaction of aluminum and water that results in the liberation of hydrogen gas could, under the appropriate circumstances, create the potential for a chemical explosion, or in other words, release enough energy to disrupt or darnage the core and lead to fission product release. From a hazards analysis viewpoint, the most serious aspect of the fuel plate- $\mathrm{H}_{2} \mathrm{O}$ reaction would be the enhanced release of fission products since the fuel matrix would be drasticaliy changed. The specific reactions are:

$$
\begin{aligned}
& 2 \mathrm{Al}+3 \mathrm{H}_{2} \mathrm{O} \longrightarrow \mathrm{Al}_{2} \mathrm{O}_{3}+3 \mathrm{H}_{2}+389 \mathrm{kcal} \\
& 2 \mathrm{H}_{2}+\mathrm{O}_{2} \longrightarrow 2 \mathrm{H}_{2} \mathrm{O}+58 \mathrm{kcal}
\end{aligned}
$$

In the first reaction, metallic aluminum is oxidized by water, liberating 3 moles of hydrogen gas for every 2 moles of aluminum reacting. The hydrogen gas, in turn, reacts with oxygen produced from radiolytic decomposition to form water. As shown, both reactions are exothermic.

Certain conditions must exist in order for the explosive $\mathrm{Al}-\mathrm{H}_{2} \mathrm{O}$ reaction to occur. The metallic aluminum must exist in a molten or dispersed form, or as finely divided particles. Such particles could conceivably result from the flexing of metal aluminum parts, particularly if embrittled by radiation. However, flexing is unlikely to occur, and even if it did, it would not be expected to produce more than a few grans of aluminum fines under even the most favorable circumstances. Indeed, no credible accident mechanism can be postulated that would produce the necessary conditions for melting and/or production of finely divided aluminum particulates.

Although the $\mathrm{Al}-\mathrm{H}_{2} \mathrm{O}$ reaction is exothermic, heat is required to initiate the reaction. The precise conditions in a reactor required to produce appreciable energy from the chemical reaction are unknown, but appear to be a combination of heat and shock wave. The heat would ensure that the metal was in a reactive state (i.e., molten), and the shock wave would disperse the fuel and cladding. 
Studies of the U-AT fuel plate and water reaction show that $174 \mathrm{cal} / \mathrm{g}$ of fuel plate are required before both damage is apparent and reaction products can be ascertained (Ivins 1963). This is equivalent to $7.24 \times 10^{-4} \mathrm{MWs} / \mathrm{g}$ of fuel plate, or 0.156 MWs/fuel plate. With the nominal core loading of 240 fuel plates, the 12-MWs pulse generated from an inadvertent maximum reactivity insertion would produce an average of only $0.05 \mathrm{MWs} / \mathrm{fuel}$ plate. As discussed earlier, a theoretical maximum nuclear excursion was postulated as depositing one-fourth of its energy in the central one-sixth or 40 plates of the core. These plates would thus experience $0.08 \mathrm{MWs} / \mathrm{plate}$ from the pulse, or about half the energy required to initiate the reaction. Or, looking at the inverse case, a total of $40 \times 0.156=6.24$ MWs would have to be deposited in the central onesixth of the core and this would require a burst energy release of $25 \mathrm{MWs}$, or about twice that available from the maximum credible excursion.

At $704 \mathrm{cal} / 9$ of fuel plate, the reaction would produce significant amounts of fission products and damage (Ivins 1963). Computed in a similar manner, the resulting total energy release would be 101 MWs, of which 25.3 would be produced in the central regions. No accident can be postulated that would credibly produce this amount of energy.

Indeed, since the minimum energy that initiates the reaction, even to a small degree, is approximately two times the maximum available from an inadvertent pulse, the $\mathrm{Al}-\mathrm{H}_{2} \mathrm{O}$ chemical reaction could not occur from such an accident and, hence, is not credible. If the reactor structure were involved in a major fire and the graphite was burning, temperatures sufficient to cause melting of the fuel and the aluminum boxes might be attained; however, the credibility of such a situation is questionable, as discussed in the following section of this report. 
GRAPHITE FIRE

A self-sustaining graphite fire requires oxygen, high temperature, and an ignition source to initiate combustion. A fire is suppressed by eliminating fuel (i.e., graphite) or oxygen or by reducing the temperature of the reactants below the combustion value. However, the potential for a fire starting depends upon the three critical parameters fuel, oxygen, and an ignition source.

\section{OXYGEN SOURCES}

Several sources of oxygen are actually or potentially available to the graphite moderator. These are:

- argon dilution air flow

- roan air--shield blocks removed

- failed beam tubes

- failed rabbit tube

- experimental gas flow.

\section{Argon Dilution Air Flow}

In the typical UTR installation, a large ventilating fan draws air inside the concrete shield through openings such as those around bean tube plugs and drainage holes. Most of the air flows between the graphite and the shield, with little flow between the individual graphite stringers, and the air flow rates range up to $250 \mathrm{cfm}$. This air dilutes and transports ${ }^{41}$ Ar produced in the reactor to a mixing chamber outside of the shieid, where it is diluted further with building exhaust air flowing at $10,000 \mathrm{cfm}$. After dilution, it is released from the roof vent.

At $250 \mathrm{cfm}$ of air flow, $2.1 \mathrm{~kg}$ of $0_{2}$ per min are potentially available to the graphite moderator. This amount of $\mathrm{O}_{2}$ could completely oxidize $800 \mathrm{~g}$ of carbon to carbon dioxide per min, yielding $6.2 \times 10^{6} \mathrm{cal} / \mathrm{min}$ (assuming the reaction goes entirely to $\mathrm{CO}_{2}$ ) based on $7800 \mathrm{cal} / \mathrm{g}$ for the heat of combustion of graphite. This much energy would be sufficient to raise $32 \mathrm{~kg}$ of graphite to $650^{\circ} \mathrm{C}$, assuming that no energy was carried off by the air flow. 
Thus, so long as the fan was running, a fire in the graphite could propagate at some rate. If the $f$ an was turned off, the rate of delivery of oxygen would fall considerably. If the reactor was otherwise normally sealed, the graphite temperature would not remain elevated. Dahl (1961) showed a rapid fall in the graphite temperature in a burning-rig experiment when the air flow to the burning zone was cut off (Nightingale 1962).

Removable Shield Blocks

It would be possible, for experimental purposes, to have access both to the graphite on top of the reactor over the fuel boxes and to the graphite of the thermal column. These locations are reached by removing the removable concrete shield blocks. A substantial part of the total reactor inventory of graphite is located in the thermal column and in the top graphite. With the shield blocks removed, the graphite would be exposed to room air and other ambient room conditions.

Failed Beam Tubes

Penetrations into the high-flux region of the Argonaut-UTR reactors are made via removable experimental beam tubes that terminate at various depths in the graphite. The beam tubes run through aluminum sleeves or liners, at least two of which are open at the inner end. These two are the liners for the deep tubes that terminate at or near the fuel boxes. All other liners are capped at the inner end.

If the beam tube were removed for any reason, with the tube plug removed there would be a hole penetrating deep within the graphite. This condition does not require a "failure" of the beam tube to admit room air freely to the graphite. The air flow to the graphite would be enhanced by the ventilating fan.

Damage to a beam tube could occur during experimental manipulation and would not be readily detected. However, since all liners except those for the deep tubes are capped at the inner end, the damage would have to involve penetrations in both tube and liner to permit air flow into the graphite. Even with a crack or small hole in the tube and liner, the air flow rate would not be very large. 
In the case of the deep beam tubes, even with the tube and plug in place, air could flow between the tube and the liner, although the flow would be greatly restricted.

Fajled Rabbit Tube

The pneumatic rabbit tube penetrates deep into the graphite and terminates at the outer surface of the fuel boxes. The tube consists of a pair of coaxial aluminum cylinders with the inner cylinder vented to the outer cylinder, which is sealed off from the interior of the reactor.

For gas to leak from the rabbit into the reactor would require that the outer tube be ruptured. Since rabbits are driven into the tube with considerable velocity, such a failure could eventually occur over the course of time. The closure of the receiving station at the outer surface of the shield must sustain the driving gas pressure. Thus, with the access lid closed, air flow down the tube through a failure at the tube end would be restricted. The major source of gas flow would be from the driver gas, which might not be air to $l$ imit the argon input into the reactor.

It is conceivable that an incorrect or misfilled gas bottle containing an elevated concentration of oxygen could be connected to the rabbit pneumatic system. However, gas cylinders containing high oxygen concentrations require regulators with threads different from those on air or nitrogen cylinders. It would take an act of ignorance or willful disregard of proper procedure to jury-rig a gas bottle of high oxygen concentration to the rabbit pneumatic drive system. Even if this did happen, for such a bottle to supply oxygen continuously would require that the valve be left open in the drive position and that an outer tube fail.

The amount of oxygen in a pure oxygen tank is limited. For example, a 50- 1 gas tank filled to 150 atm contains 300 moles of oxygen, which is sufficient to completely oxidize $3.6 \mathrm{~kg}$ of carbon to carbon dioxide, yielding 28 Mcal. Should all the improbable events outlined above occur and all the available energy be deposited in the graphite, it could heat as much as $140 \mathrm{~kg}$ of graphite to ignition $\left(650^{\circ} \mathrm{C}\right)$. More than $3.6 \mathrm{~kg}$ of graphite would be consumed under incomplete combustion to a mixture of $\mathrm{CO}$ and $\mathrm{CO}_{2}$. Nevertheless, an 
oxygen bottle error could only initiate a graphite fire. The fire would have to propagate with air brought in by the ventilating system or from some other external source before enough graphite could be heated to present a significant hazard to the fuel.

Energy transfer to the graphite would not be $100 \%$ efficient, and the amount of graphite actually heated to ignition would be substantially less than $140 \mathrm{~kg}$. Even to begin, this scenario would require the simultaneous occurrence of a gas bottle error, a failed rabbit tube, and early ignition. If ignition were delayed, the shield ventilating system would sweep the oxygen out of the reactor.

Experimental Gas Flow

It is conceivable that an experiment would require a flow of oxygencontaining gas in an apparatus within the reactor. In such a case, equipment failure could introduce oxygen into the graphite. Unless the apparatus was isolated by placement in a closed beam tube or was monitored continuously, such a failure could lead to a continuous supply of oxygen being delivered to the graphite. However, as noted in the previous section, the contents of an oxygen tank are limited. The oxygen in a tank would support enough combustion to raise a considerable amount of graphite to ignition temperature, but further propagation of a fire would require another source of oxygen such as ventilation (argon dilution) air flow.

\section{FUEL SOURCES}

All classes of flammable materials--solids, liquids, and gases--are potentially available to a research facility, but their use is usually restricted to prevent their introduction into the reactor. However, for experimental purposes or during maintenance or modification of the reactor, flamable materials in various amounts may be deliberately or accidentally introduced into the reactor. Any deliberate introduction of burnable material into the reactor may be assumed to be only for experimental purposes and thus limited in amount. It is difficult to set a limit on the amount of flamable material that might be introduced accidentally especially as a gas or liquid. 
The potential fuel sources to be discussed are:

- reactor graphite

- liquid fuels

- gaseous fuels

- solid fueis.

\section{Reactor Graphite}

The most obvious source of fuel for a reactor fire in the Argonaut-UTR is the graphite itself. If the graphite can be made to burn, it will yield $7800 \mathrm{cal} / \mathrm{g}$ (Nightingale, p. 327) in the conversion of carbon to carbon dioxide.

The specific heat of graphite is given by (Nightingale, p. 122) in tabular form. The data can be fitted to the quadratic equation:

$$
C_{p}=1.86 \quad\left(8.34 \times 10^{-3} \mathrm{~T}\right)-\left(5.27 \times 10^{-6} \mathrm{~T}^{2}\right)
$$

in which $C_{p}$ is the specific heat in $c a l / g^{\circ} \mathrm{C}$ at any temperature $T$, expressed in ${ }^{\circ} \mathrm{C}$, over the range $25^{\circ}$ to $650^{\circ} \mathrm{C}$. The energy required to heat the graphite from $25^{\circ}$ to $650^{\circ} \mathrm{C}$ can be obtained by integrating Equation ( 8 ) and is calculated as $203 \mathrm{cal} / \mathrm{g}$.

Burning experiments performed with graphite (Nightingale, p. 416) indicate that at $650^{\circ} \mathrm{C}$, graphite will burn readily if sufficient oxygen is supplied. From the above data, the combustion of $1 \mathrm{~g}$ of graphite will raise $38 \mathrm{~g}$ to the ignition temperature if no energy is lost. The energy of burning actually delivered to the graphite would undoubtedly be mucin less, but clearly once the graphite is ignited, it will continue to burn as long as sufficient oxygen is available or the fire is not extinguished.

\section{Liquid Fuels}

Liquid combustibles would not normally be introduced into the reactor in quantity but would be 1 imited to small samples for neutron activation analysis, reactivity measurements, neutron scattering, or other experiments. Introduction of larger amounts would be the result of accicent or sabotage.

A small quantity of flammable liquid spilled without detection might, if ignited, provide enough initial energy to ignite a small portion of the 
graphite. Heats of combustion of organic solvents range between about 5 and $10 \mathrm{kcal} / \mathrm{g}$, which potentially could raise between 25 and $50 \mathrm{~g}$ of graphite to ignition temperature per gram of solvent burned. The actual heating would undoubtedly be much less.

In addition to directly burning the solvent, spilled flammable liquid could evaporate, producing a flamable or explosive vapor.

Gaseous Fuels

There are few instances in which a flammable gas would be introduced into the reactor. A possible case might be the flow of gas needed for a gas-filled proportional counter. Such a detector would not normally be installed within the reactor, because saturation effects due to the high gamma flux would make its operation difficult.

An example of the accidental introduction of a flamable gas might be through an acetylene torch opened or left open by error. If the torch were at the open thermal column or an open beam tube, a considerable volume of gas might be brought into the reactor. Properly mixed with oxygen, acetylene requires a relatively small spark to initiate ignition. Acetylene yields about $14 \mathrm{kcal} / 1$ of gas burned, which would raise about $70 \mathrm{~g}$ of graphite to ignition if all of the energy could be delivered. An acetylene tank charged to 2000 ps $i$ would contain approximately 60001 of deliverable gas which, if completely burned, would yield sufficient energy to raise $410 \mathrm{~kg}$ of graphite to ignition.

Thus, even though the actual hazard of gaseous fue is may be small, the potential energy for bringing a substantial amount of graphite to ignition may be available in or around a research reactor facility.

Solid Fuels

It is not uncommon for flammable solids to be inserted into research reactors, although these materials are not thought of as flammable. For example, the plastic from which the rabbit is typically made will burn if ignited, as will most plastics used for experimental equipment.

Some metals will ignite spontaneously under suitable conditions if the surface-to-volume ratio becomes sufficiently large. Zirconium and uranium 
metal fires have been reported in scrap bins because of this phenomenon. While large amounts of small pieces of pyrophoric metals would not normally be left in research reactors, such a fire is not physically impossible. Phyrophoricity is also a potential ignition source and will be mentioned again in the following section.

Various chemical mixtures have the potential for reacting and releasing considerable energy. An obvious example is the mixture of finely divided aluminum with the oxide of a less reactive metal. It is hard to imagine such a hazardous mixture being knowingly or deliberately introduced into a reactor. However, given a combination of ignorance and enthusiasm at a reactor used by incompletely trained students, such an occurrence could not be completely ruled out. Even so, in any chain of events leading to a graphite fire, there are some steps between introducing a material such as thermite into a reactor and actually having it ignite by further mischance.

IGNITION SOURCES

Many events can be postulated to lead to the production of a localized high temperature, either directly or in combination with some other event. To pose a significant problem, however, the ignition event must occur at the location of and in the presence of a material that can readily ignite and can burn long enough to ignite a larger fuel supply. Some of the ignition sources considered below are sufficiently energetic to potentially start the graphite burning directly. These ignition sources are:

- Wigner effect

- electrical malfunction

- pyrophoric material

- friction

- explosive

- nuclear heating

- power excursion

- external flame

- building fire. 


\section{Wigner Effect}

Nightingale (1962, p. 328) gives the initial rate of energy accumulation in graphite at $30^{\circ} \mathrm{C}$, due to neutron irradiation in a reactor, as $0.5 \mathrm{cal} / \mathrm{g}$ for I MWd/ton burnup in the fuel immediately adjacent to the graphite. This value falls as exposure accumulates or as the temperature of the graphite during irradiation rises. The value at $50^{\circ} \mathrm{C}$ at low exposure is given as about 0.3 cal/g per MWd/ton. At full power, the Argonaut-UTR operates with a center island graphite temperature of approximately $65^{\circ} \mathrm{C}$. The thermal neutron fluence equivalent for fuel burnup is $6.4 \times 10^{17} \mathrm{n} / \mathrm{cm}^{2}$ per Mwd/ton (Nightingale 1962). Thus, taking the $50^{\circ} \mathrm{C}$ value as appropriate, the rate of energy storage

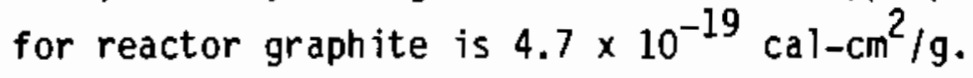

The highest flux in Argonaut reactors occurs in the graphite in the central portion of the core. At full power $(100 \mathrm{~kW})$, the thermal flux is about $10^{12} \mathrm{n} / \mathrm{cm}^{2}-\mathrm{s}$. Thus, the graphite in the center island will store energy at approximately $4.7 \times 10^{-7} \mathrm{cal} / \mathrm{g}$-s or $0.041 \mathrm{cal} / \mathrm{g}$-day at full power.

The capacity factor for university research reactors runs much closer to zero than to $100 \%$. For example, the University of Washington Argonaut-UTR is presently operating well below $10 \%$ capacity. (a) The UCLA Argonaut has logged $5,000 \mathrm{kWd}$ in the 7 years from 1973 through 1979, which corresponds to a capacity factor of $2 \%$ (UCLA 1980). The UCLA reactor has operated at $100 \mathrm{~kW}$ since 1963 , which through 1980 at the same capacity factor, would correspond to $1.2 \times$ $10^{4} \mathrm{kWd}$. For this reactor, then, the center island graphite may have accumulated a stored energy of $5 \mathrm{cal} / \mathrm{g}$. This level of energy is insufficient, if released, to heat the graphite by more than a trivial amount.

\section{Electrical Malfunction}

A normal part of the use of a research reactor such as the Argonaut-UTR includes the installation of instrumentation. Either detectors or experimental apparatus may be installed deep within the graphite moderator. Unlined vertical access holes from the top of the reactor penetrate through the graphite of the center island and are routinely used for experimental access. Detectors

(a)W. P. Miller, private communication. 
requiring high voltage may be installed at the level of the center island. An electrical malfunction could cause an electric arc. The current drain would have to exceed the fuse capacity before fuses would blow to terminate the arc. While the energy generated by such an arc would not be likely to heat the graphite directly by very much, it could start a fire in electrical insulation or other adjacent flamable material.

For the fire to propagate in the graphite, a steady flow of oxygen would be required. Unless there was forced flow from some external source (e.g., the fire started in the major flow path of the argon dilution air), the limited oxygen supply would limit the propagation of fire in the graphite. Thus, unless the fire started at the interface between the graphite and the shield, it would be unlikely to propagate.

If an electrical malfunction occurred in conjunction with an oxygen leak, a fire could propagate more deeply within the graphite until the oxygen was turned off or the supply exhausted. However, although some graphite would burn, air flow deep in the graphite is limited, and propagation of the fire there would be inhibited.

\section{Pyrophoric Materials}

As was discussed earlier, some metals, when finely divided, spontaneously ignite in air. The energy yield for the oxidation of these metals is on the order of $1 \mathrm{kcal} / \mathrm{g}$, which could potentially raise $5 \mathrm{~g}$ of graphite to the ignition temperature. However, it is highly unlikely, even assuming gross carelessness, that very large amounts of pyrophoric material would be spilled into a reactor since there is no particular reason to do an experiment with large amounts of finely divided metals. Any machining of such metals would not be expected to take place at the reactor, so such a source can also be discounted.

\section{Friction}

The energy dissipated by friction can sometimes be partially expended as a spark discharge due to static electricity. The amount of energy available from friction is not large, and bulk materials are not noticeably at risk for ignition. However, spark discharges in the presence of combustible or explosive vapors represent a substantial hazard. Since graphite is an excellent 
conductor of electricity, apparatus in contact with it would be well grounded and static potentials would therefore be less likely to build up.

Explosive

Normal operating procedures should prohibit the presence of explosives in or near a reactor. However, it is conceivable that some experiments, such as radiography of an explosive bolt or round of ammunition, might occasionally bring a small amount of explosive to the reactor. If handled with care, such an object should present no problem, but a hazard due to carelessness can never be ruled out. Since the amounts of explosive would presumably be small, the total energy release would prevent a greater hazard to personnel than to the graphite of the reactor. An explosion would not be an ignition source unless some readily ignitable material, such as an organic liquid or vapor, was nearby.

Only in the case of sabotage would large amounts of explosive material deliberately be introduced into a reactor. It is highly unlikely that individuals would bring explosives to the reactor for any purposes, including experimentation. Thus, the hazard due to the accidental introduction of explosives seems remote.

Nuclear Heating

Strongly exothermic materials that can undergo nuclear reactions, such as fission foils, are routinely irradiated in a research reactor facility. Many grams of enriched uranium or other fissile material would be needed to generate sufficient energy to overheat the graphite, and the problem would be one of a nuclear excursion, as discussed earlier in this report.

If a fission foil is composed of an aluminum jacket surrounding a U-Al alloy, the aluminium greatly dilutes the uranium. For example, a 1-cm-diameter foil that is $1 \mathrm{~min}$ thick would, in a thermal flux of $10^{12} \mathrm{n} / \mathrm{cm}^{2}-5$, heat adiabatically at a rate estimated to be somewhat less than $1^{\circ} \mathrm{C} / \mathrm{hr}$ for every microgram of fissile isotope and would bring the foil to the melting point in an irradiation of $1 \mathrm{hr}$. Fission foils containing several grams of fissile material have been used in experiments at the Argonaut-UTR. (a) The loadings

(a) W. P. Miller, private comunication. 
in fission foils appear to span a wide range and overheating to a temperature high enough to ignite various flammable substances seems well within the realm of possibility. Because of the low specific heat of metals compared to graphite, it is unlikely that a foil could serve as a primary heat source to heat the graphite to ignition before the foil melted. Inadvertently neglecting to remove a foil from the reactor, raising the reactor power above the level at which the foil was intended to operate, or dropping one into the reactor could lead to such an overirradiation.

Some glasses contain a significant amount of boron. The $(n, a)$ reaction in $10_{B}$ is strongly exothermic (2.8 MeV) and in a flux of $10^{12} \mathrm{n} / \mathrm{cm}^{2}-\mathrm{s}$ is capable of generating sufficient energy to bring the glass to a very high temperature in a relatively short time. Borosilicate glass is a common substance and could readily be introduced and lost in the reactor. All in all, nuclear heating as an ignition source cannot be ruled out.

\section{Power Excursion}

As discussed earlier, fuel temperatures approaching $586^{\circ} \mathrm{C}$ could conceivably result from a nuclear excursion. Such temperatures are below the ignition temperature of graphite but exceed the ignition temperatures or flash points of many common organic compounds. Although it is possible to have a large excursion coincident with a large enough spill of organic liquid within a reactor to ignite the graphite, the circumstances are not considered credible.

\section{External Flame}

The installation of experimental equipment or the maintenance and modification of a reactor may require the use of open flames. For example, the weiding of steel may bring a high-temperature source into contact with the graphite or other reactor components.

In the presence of an interacting fault, such as a spill of flammable liquid or the overheating of a portion of the graphite acting as a heat sink, some of the graphite may be brought to ignition temperature. Such an event seems most likely to occur near the outside of the graphite, where ample room air is 
available. By the same token, the outside is accessible for the use of standard fire-fighting techniques, and there should be ample time for corrective action should a fire get started.

Building Fire

A major building fire could subject a reactor to high external temperatures, although considerable protection would be afforded by the concrete biological shield. Although the beam tubes provide access to the interior graphite, they are long, and unless burning material fell into an open vertical hole, there would not seem to be any excess risk associated with a closed beam tube during a building fire.

On the other hand, if a building fire were to start while the shield blocks were removed, the exposed graphite would be at risk. The probability of these independent events occurring together should be very small. However, a common-mode cause cannot be dismissed. It is conceivable that the circumstances that lead to removal of the shield blocks could also increase the risk of a building fire. If the work spanned several weeks, the reactor might be unattended over weekends. For example reactor modifications for installation of experimental apparatus might result in the accumulation of flammable materials around the reactor, enhancing the fire risk during that period. Any fire starting then might burn for a considerable length of $t$ ime before it was discovered and firefighters arrived.

\section{DESIGN BASIS ACCIDENT}

The various events examined so far that could contribute to or initiate a graphite fire are all of low probability. However, insufficient data is available for quantifying the probabilities.

Two other scenarios involve a chain of events that would lead to the nearly simultaneous interaction of an oxygen supply, fuel, and an ignition source. That is, the chain of events in each scenario has a common cause. These scenarios are the failure of an experimental apparatus, and a building fire with exposed graphite. 


\section{Apparatus Failure}

For this scenario, it is supposed that an experiment requires the continual flow of gas highly enriched in oxygen in an apparatus placed directly within the center island graphite moderator. It is further supposed that the apparatus has glass components that have been made of borosilicate glass to control thermal expansion.

Commercial borosilicate glasses have a boron content of about $4 \%$ by weight. In a flux of $10^{12} \mathrm{n} / \mathrm{cm}^{2}-\mathrm{s}$, there is enough $10_{B}$ in the glass to produce substantial amounts of internal heating by the reaction, ${ }_{5}^{10} B(n, \alpha){ }_{3}^{7} L i$, $\mathrm{Q}=2.8 \mathrm{MeV}$. In the temperature range between $25^{\circ}$ and $1000^{\circ} \mathrm{C}$, energy generation in the glass would average about $300 \mathrm{cal} / \mathrm{g}-\mathrm{hr}$. In this temperature range, the specific heat of the glass would allow adjabatic heating to $1000^{\circ} \mathrm{C}$ in one hour of irradiation at $10^{12} \mathrm{n} / \mathrm{cm}^{2}-\mathrm{s}$. This is substantially above the softening point for these glasses.

Heating, of course, would not be adiabatic. Considerable amounts of energy would be lost by radiation and conduction. The result of nonadiabatic heating would be to slow the rate of heating and to limit the temperature the glass could reach. As a result, the glass would not soften and failure would be limited to mechanical causes.

It is considerably less likely that an accident that leads to breaking of the apparatus would occur with the equipment unattended, since producing mechanical breakage requires manipulation of the apparatus. Thus, although breakage could lead to oxygen release, electric arcing, and initiation of a fire, immediate response by the experimenters would limit the consequences. Building Fire

For this scenario, it is supposed that students are installing an extensive experiment into the graphite of the center island. Thus, the top concrete shield blocks are removed and the graphite is extensively exposed. In addition, considerable quantities of fabrication supplies, some of which are flammable, are distributed around the work area. The work is extensive enough to span several days at the minimum and perhaps several weeks. As a result, the reactor graphite is left exposed and unattended over the weekend. 
The initiating event that leads to igniting the graphite is a building fire on the weekend. The fire would spread to whatever flammables were distributed around the reactor work area. Since opening shield would have exposed the graphite to room air, the graphite could be ignited.

Overhead foam, deluge, or sprinkler systems are not universally employed at Argonaut-UTR facilities. Thus, once a fire started, its spread and intensity would be limited only by the distribution of combustibles and the delay time before an alarm was sounded and firefighters responded. If the intensity of the fire was low because the amount of combustibles available was relatively small, it might do little more than ignite the graphite. In that case, the graphite would slowly burn in an expanding front, producing heat but little smoke. Building ventilation would keep the air replenished, and such discharge smoke and odor as would be noticed in the vicinity would be the only immediate indication of a problem.

Depending on the frequency of inspection of the facility on the weekends by the roving security guard, there could be several hours of burning time. The graphite fire could be expected to behave like a normal fire. Much of the heat would rise into the building, so heating of the graphite would be slower than in the case of adiabatic combustion.

The center graphite is immediately adjacent to the fuel boxes, which may be drained during shutdown. Thus, depending on the length of time before discovery of the fire, the aluminum fuel boxes and fuel could be at risk for melting.

\section{Summary}

Given all of the events that must occur before a graphite fire can be started, it seems highly unlikely that one would occur. Nevertheless, the two scenarios described above have some potential for leading to such a fire. In the case of apparatus failure, it appears unlikely that any graphite fire that did get started would burn long enough to put the fuel at risk. In the case of a building fire, unless the fire was severe, with the whole building extensively involved, it again appears unlikely that enough time would elapse without detection of the fire to permit ignition of the graphite and subsequent fuel melting. 


\section{FUEL-HANDLING ACCIDENT}

At some time during the 1 ifetime of an Argonaut-UTR reactor, core fuel changes may be undertaken. Fuel elements are removed singly and, since the reactor is normally shut down and drained during this operation, there is no criticality hazard. A variety of credible scenarios can be developed in which a fuel element is dropped and one or more of its constituent fuel plates are damaged during fuel-handling operations, resulting in a release of radioactivity. Indeed, a fuel-handling accident scenario appears to be the only realistic postulated accident that might result in significant radiation exposure or radioactive contamination.

The scenario developed below is a "worst case" situation, involving two mutually independent events, extremely unfavorable meteorology with a downwind observer at the point of maximum exposure, and a large fission product inventory in the fuel. Thus, the results should be interpreted as the maximum possible, with appropriate down-scaling required to evaluate accidents with lesser hazard potential.

POWER HISTORY AND FISSION PRODUCT INVENTORY

Many scenarios can be developed that would result in damage to a fuel plate or element, with subsequent release of radioactivity to the environment and exposure to individuals outside the reactor building (i.e., offsite). For the sake of simplicity, the scenario assumed here involves the removal of a fuel element from the core immediately after shutdown following an extended operation period of 1 year at a power level of $100 \mathrm{~kW}$, or $36.5 \mathrm{MWd}$. These operating parameters are extraordinary when viewed in the context of estabijshed Argonaut/UTR operating experience, which has typically shown capacity factors of $2 \%$ or less. However, since operation at, $100 \%$ capacity for a year is not precluded by license or other conditions, it: is reasonable to assume these parameters as "worst case" conditions from the standpoint of fission product inventory.

An Argonaut/UTR core has 24 fuel elements, each with the capacity for 11 fuel plates, for a total capacity of 264 fuel p ates. However, a typical 
core loading might contain only about 10 plates per element, for a total of 240 plates. (With 10 plates per element, the core loading would be $3.26 \mathrm{~kg}$ of ${ }^{235} \mathrm{U}$, approximately the minimum critical mass for a cold clean core.) The average power density across the core would be relatively constant, but there would be slight variations as a result of variation in reflector savings, location of fuel plates, experiments, and so forth. While in general the average flux would not vary appreciably from element to element, for conservatism a value of 1.5 was chosen for the ratio of the power density at the location of the fuel element involved in the hypothetical accident to the average power density in the core.

The fraction of the total core inventory, $f$, in any given fuel element can be determined from the simple relationship

$$
f=\frac{n_{e} r}{n_{\text {tot }}}
$$

where $n_{e}$ is the number of fuel plates in the element

$$
\begin{aligned}
& n_{\text {tot }} \text { is the total number of fuel plates in the reator } \\
& r \text { is the ratio of power density at the location of the fue } 1 \\
& \text { element to the average power density in the core. }
\end{aligned}
$$

Assuming a minimum core loading of 240 plates, with 11 in the element under consideration, and assuming that the value of $r$ is 1.5 as discussed above, then

$$
f=\frac{11 \times 1.5}{240}=0.07
$$

or up to $7 \%$ of the core activity in a single element. This is a maximum, for it assumes a) a minimum number of plates (240) in the core, b) maximum plate loading in the element, and c) maximum power density or burnup of the element in question. The typical or average fuel element would contain only about $4 \%$ of the fission product inventory. The activities following 100-kW operation for 1 year ( $36.5 \mathrm{MWd}$ ) were calculated for the noble gases and radioiodines for a single fuel element containing $7 \%$ of the core inventory and are shown in Table 3 at 0 and $48 \mathrm{hr}$ after shutdown. 
TABLE 3. Gaseous Fission Products in the Argonaut-UTR Element Containing the Greatest Activity Following Operation at $36.5 \mathrm{MWd}$

\begin{tabular}{|c|c|c|c|}
\hline Nuclide & $-\mathrm{T}_{1 / 2}$ & $\begin{array}{l}\text { Curies } \\
\text { at Shutdown }\end{array}$ & $\begin{array}{c}\text { Curies } \\
48 \mathrm{hr} \text { Postshutdown } \\
\end{array}$ \\
\hline $85 m_{K r}$ & $4.4 \mathrm{~h}$ & 78.5 & $4.1 \times 10^{-3}$ \\
\hline${ }^{85} \mathrm{Kr}$ & $10.8 \mathrm{y}$ & 1.1 & 1.1 \\
\hline${ }^{87} \mathrm{Kr}$ & $1.3 \mathrm{~h}$ & 140 & $5.5 \times 10^{-10}$ \\
\hline $88_{k r}$ & $2.8 \mathrm{~h}$ & 215 & $1.4 \times 10^{-3}$ \\
\hline $133 m \times e$ & $2.3 d$ & 11.2 & 6.0 \\
\hline${ }^{133} x e$ & $5.3 \mathrm{~d}$ & 400 & 310 \\
\hline $135 m_{x e}$ & $0.3 \mathrm{~h}$ & 62 & -- \\
\hline${ }^{135} \mathrm{xe}$ & $9.1 \mathrm{~h}$ & 397 & 9.9 \\
\hline${ }^{131} 1_{I}$ & $8.1 \mathrm{~d}$ & 164 & 140 \\
\hline 132 I & $2.3 \mathrm{~h}$ & 244 & $1.1 \times 10^{-4}$ \\
\hline${ }^{133}$ I & $20.3 \mathrm{~h}$ & 399 & 81 \\
\hline $134 \mathrm{I}$ & $0.9 \mathrm{~h}$ & 424 & - \\
\hline${ }^{135}{ }_{I}$ & $6.7 \mathrm{~h}$ & 327 & 2.6 \\
\hline
\end{tabular}

\section{ACTIVITY RELEASE FRACTION}

The amount of activity released would depend upon the circumstances of the accident, primarity on the temperature and exposed surface area of the fuel. Following normal operation even at full power, the fuel temperature would be low and diffusion would be essentially zero. Hence, any release of fission products would be from the surface of the fuel, through kinetic energy imparted by the fission fragment recoil. This places a finite limit on the range of the recoil.

The uranium-aluminum alloy predominately used for the Argonaut-UTR fuel consists of particles of $\mathrm{UAl}_{4}$ dispersed in an aluminum matrix (Kalish et al. 1960). Several investigators (Weber and Hirsh 1956; White, Beard and Willis 1957; Keller 1960) have examined the behavior of fission fragments in aluminum 
matrix fuel, and their models appear applicable to the Argonaut-UTR case. Weber and Hirsh (1955) have reported the range of fission fragment recoils in a luminum as $1.37 \times 10^{-3} \mathrm{~cm}$.

For conservatism, it can be assumed that all the gaseous activity produced within the range of recoil particles would be able to escape from the fuel. Assuming an accident in which the entire surface area of all 11 plates in a fuel element was denuded of cladding, the total surface area exposed would be $10,500 \mathrm{~cm}^{2}$, and the volume of fuel from which the radioactivity could escape would be

$$
1.37 \times 10^{-3} \mathrm{~cm} \times 10,500 \mathrm{~cm}^{2}=14 \mathrm{~cm}^{3}
$$

The total fuel volume for the 11 plates is $525.7 \mathrm{~cm}^{3}$. Hence, assuming uniform distribution of fission products, $14 \div 525.7$ or $2.7 \%$ of the gaseous activity in a single element could escape. This is an upper limit value and is equivalent to a $100 \%$ gap activity release or $100 \%$ cladding failure or effectively postulating that through some unstated mechanism $2.7 \%$ of the activity in a single fuel element would be released to the environment. The example postulates $100 \%$ release of the gaseous activity (i.e., radioisotopes of krypton, xenon, and iodine) produced within fission fragment range of the surface. This is a conservative assumption given the low fuel temperature and the fact that not all the fission gases would move out of the fuel. Because of the low temperature, any release of other fission products, including the semivolatiles, such as strontium, would be negligible (Cordes 1968; Hilliard 1959;

Thompson 1964).

\section{DOSE ESTIMATES}

Doses to an observer downwind from the accident would be primarily from the noble gases and radioiodines. The dose from the noble gases would be largely external, resulting from inmersion in a cloud containing the radioxenons and radiokryptons. The radioiodines are biologically active and would be taken up by the thyroid gland, which becomes the critical organ for exposure. 
The calculated doses to the hypothetical maximally exposed individual offsite are shown in Table 4. These values are highly conservative and represent worst case conditions. A release fraction $2.7 \%$ of the fission gases and radioiodines from a single element damaged during handling was assumed. No credit was taken for radioactive decay, plateout or other mechanisms that would reduce the activity reaching a downwind observer. A ground-level release was assumed,

TABLE 4. Activity and Dose Equivalents from Maximum Credible Fuel-Handling Accident

\begin{tabular}{|c|c|c|c|c|}
\hline Nuclide & $\begin{array}{l}\text { Curies } \\
\text { Released (a) }\end{array}$ & $\begin{array}{c}\text { Plume } \\
\text { Concentration, } \\
\mathrm{Ci} / \mathrm{m}^{3}(\mathrm{~b}) \\
\end{array}$ & $\begin{array}{r}\text { Dos } \\
\text { Equiva } \\
\text { re } \\
\end{array}$ & \\
\hline $85 m_{K r}$ & 2.1 & $5.9 \times 10^{-6}$ & 0.11 & \multirow{8}{*}{ to total body } \\
\hline${ }^{85} \mathrm{Kr}$ & 0.03 & $8.3 \times 10^{-8}$ & -- & \\
\hline${ }^{87} \mathrm{Kr}$ & 3.8 & $1.1 \times 10^{-5}$ & 1.04 & \\
\hline $88_{\mathrm{Kr}}$ & 5.8 & $1.6 \times 10^{-5}$ & -- & \\
\hline $133 m_{x e}$ & 0.3 & $8.4 \times 10^{-7}$ & -- & \\
\hline $133 \mathrm{xe}$ & 10.8 & $3.0 \times 10^{-5}$ & 0.19 & \\
\hline $135 m_{x e}$ & 1.7 & $4.7 \times 10^{-6}$ & -- & \\
\hline${ }^{135} \mathrm{xe}$ & 10.7 & $3.0 \times 10^{-5}$ & 0.63 & \\
\hline
\end{tabular}

Total whole-body dose equivalent from

1.97 rem noble gases

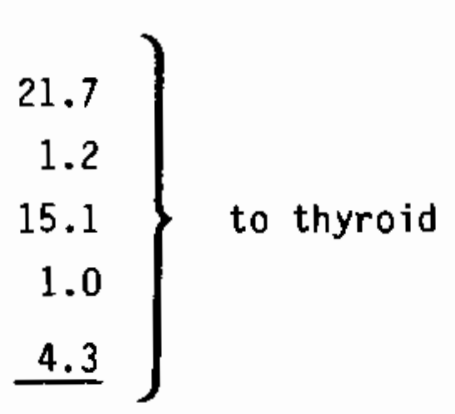

Total thyroid dose equivalent from radioiodines

43.3 rem

(a) Assumes no decay after shutdown and $2.7 \%$ release from a single fuel element containing $7 \%$ of the core inventory following operation for 36.5 MWd.

(b) Assumes 1-hr release time and $x / Q=0.01$. 
occurring over a relatively short time period ( $1 \mathrm{hr}$ ) during highly stable atmospheric conditions. The value of $X / Q$ at the point of the observer was taken to be $10^{-2} \mathrm{~s} / \mathrm{m}^{3}$, an extremely conservative value.

Radionuclide concentrations at the point of the observer were calculated by

$$
c_{i}=\frac{A_{i} f \times / Q}{t}
$$

where $C_{i}$ is the concentration of the $i$ th nuclide released in $\mathrm{C} i / \mathrm{m}^{3}$

$A_{i}$ is the activity of the ith nuclide in the fuel, in curies

$f$ is the fraction of activity released (0.027)

$x / Q$ is the atmospheric dispersion factor $\left(10^{-2} \mathrm{~s} / \mathrm{m}^{3}\right)$

$t$ is the $t$ ime of release $(3600 \mathrm{~s})$.

Putting in the contsants, Equation (10) becomes

$$
C_{j}=7.5 \times 10^{-8} A_{i}
$$

Inmersion dose rates can be calculated from the following equation, adapted from the International Cormission on Radiological Protection (ICRP 1960):

$$
c_{i}=\frac{1.04 \times 10^{-3}}{\Sigma(E)_{i}} \frac{d R}{d t}
$$

where $\Sigma(E)_{\mathfrak{i}}$ is the effective absorbed energy per disintegration of the $i$ th nuclide, in $\mathrm{MeV}$

$\frac{d R}{d t}$ is the whole-body dose equivalent rate, in rem/hr.

The immersion dose can be calculated by rearranging terms and integrating over $t$ ime $t$ : 


$$
\begin{aligned}
& \frac{d R}{d t}=\frac{\sum(E)_{i} C_{i}}{1.04 \times 10^{-3}} \\
& R=\int_{0}^{t} 962 \quad(E)_{i} C_{i} d t
\end{aligned}
$$

Combining Equations (11) and (13) gives

$$
R=\int_{0}^{t} 7.2 \times 10^{-5} \Sigma(E)_{i} A_{i} d t
$$

which, integrated over the $1-\mathrm{hr}$ release period, becomes

$$
R=7.2 \times 10^{-5} \quad(E)_{j} A_{i}
$$

While the dose from the noble gases would be largely external, from immersion in the cloud, the dose from radioiodines would be largely an internal dose to the thyroid, following inhalation of these nuclides. The thyroid dose equivalent was determined from the relationship

$$
H=C_{i} V t f_{1} D_{i}
$$

where $H$ is the total integrated lifetime dose equivalent to the thyroid, in rem

$C_{i}$ is the concentration of each specific radioiodine isotope in the cloud, in $\mathrm{C} / \mathrm{m}^{3}$

$V$ is the breathing rate $\left(1.2 \mathrm{~m}^{3} / \mathrm{hr}\right.$ ICRP 1960)

$t$ is the time required for passage of the cloud ( $1 \mathrm{hr}$ )

$f_{1}$ is the fraction of the activity inhaled that reaches the thyroid (0.23 ICRP 60)

$D_{i}$ is the dose conversion factor in $\mathrm{rad} / \mathrm{C} i$ for each individual, iodine isotope, converted to dose equivalent by assuming a quality factor of 1 (Kathren 1964).

Putting in the constants and combining Equations (11) and (15) yields 


$$
H=2.1 \times 10^{-8} \mathrm{~A}_{j} \mathrm{D}_{i}
$$

Although the dose calculations were based on a release over a period of $1 \mathrm{hr}$, in the derivation of Equations (14) and (16) the time of exposure drops out, Teaving only the activity released. Thus, the calculations would be valid irrespective of the time base for the release, and would fit a puff or instantaneous release as well as a protracted release.

The calculations reveal that even for a fuel-handling accident based on highly conservative assumptions, whole-body dose equivalents from noble gases to an exposed downwind observer would be small, on the order of 2 rem or less, and lifetime thyroid dose-equivalent comitments would be on the order of 43 rem. These calculated dose equivalents represent an upper limit, and it is extremely unlikely that these independent events would combine to produce the conditions necessary for this accident. More realistic accident scenarios would result in whole-body dose equivalents from noble gas immersion or thyroid doses fram iodine intake one to several orders of magnitude lower. 


\section{ACKNOWLEDGEMENT}

The authors wish to thank Urban Jenquin for assistance with the computer calculations and Jan Baer for editorial assistance. 


\section{REFERENCES}

Advanced Technology Laboratories (ATL). 1959. Hazards Analys is UTR-10 Standard Model. ATL-137, Mountain View, California.

Baker, L., Jr., and R. C. Li imatakinen. 1973. "Chemical Reactions." In Reactor Materials and Engineering, Vol. 1 of The Technology of Nuclear Reactor Safety, pp. 419-523. The M.I.T. Press, Cambridge, Massachusetts.

Batt les, D. W., and E. G. Joki. 1961. Summary Report on the Hazards of the UTR Test Reactor. ATL-D-619, Advanced Technoloigy Laboratories, Mountain View, California.

Cordes, 0. L. 1968. "Comparison of Fission Product Releases from the Destructive Tests of Two SNAP 10A/2 Reactors." In Proceedings of First International Congress on Radiation Protection, eds.W. S. Snyder, et al. Pergamon Press, 0xford.

Dahl, R. E. 1961. Experimental Evaluation of the Combustion Hazard to the Exper imental Gas-Cooled Reactor - Preliminary Burning Rig Experiments, HW-67792. General Electric Company, Richland, Washington.

Dietrich, J. R. 1955. "Experimental Determinations of the Self-Regulation and Safety of 0perating Water-Moderated Reactors." In Legal Administrative, Hea] th and Safety Aspects of Large-Scale Use of Nuclear Energy, Vol. 13 of Proceedings of the International Conference on the Peaceful Uses of Atomic Energy. United Nations, New York.

Duncan, J. M. 1958. University of Florida Training Reactor Hazards Summary Report. NP-7042, Technical Information Center, Oak Ridge, Tennessee.

Edlund, M. C., and L. C. Noderer. 1957. Analys is of BDRAX Experiments and Application to Safety Analyses of Research Reactors. CY-57-7-92, 0ak Ridge National Laboratory, Oak Ridge, Tennessee.

Elliott, R. P. 1965. Constitution of Binary Alloys, First Supplement. McGraw-Hill, New York.

General Electric Co. 1962. Additional Analys is of the S1-1 Excursion. 100-19313. NRTS, Arco, 1daho.

Greene, N. M., et al. 1976. AMPX: A Modular code System for Generating Coupled Multigroup Neutron-Gamina Libraries from ENDF/B. ORNL/TM-3706, 0ak Ridge Nationa L Laboratory, Oak Ridge, Tennessee.

Greene, M. M., and C. W. Craven, Jr. 1969. XSDRN: A Discrete Ordinates Spectral Averaging Code. ORNL-TM-2500, 0ak Ridge Natiuonal Laboratory, Oak Ridge, Tennessee. 
Harper, W. R. 1961. Basic Principles of Fission Reactors. Interscience Publishers, Inc., New York.

Hilliard, R. K. 1959. Fission Product Release from Uranium Heated in Air. HW-60689, General Electric Company, Richland, Washington.

International Commission on Radiological Protection (ICRP). 1960. "Report of Comittee II on Permissible Dose for Internal Radiation (1959)." Health Phys. 3:1.

Ivins, R. 0. 1963. "A Study of the Reaction of Aluminum/Uranium Alloy Fuel Plates with Water Initiated by a Destructive Reactor Transient." Trans. Amer. Nuc. Soc. 6(1):101-102.

Kalish, H. S. et al. 1960. "Uranium Alloys." In Materials, Vol. 1 of Reactor Handbook, ed. C. R. Tipton, Jr, 2nd ed. Interscience PubTishers, Inc., New York.

Kathren, R. L. 1964. "Activity and Thyroid Dose from Radioiodines." Nucleonics $22(11): 60$.

Keller, D. L. 1960. "Dispersion Fuels." In Materials, Vol. 1 of Reactor Handbook, Ed. C. R. Tipton, Jr. 2nd ed. Interscience Publishers, Inc., New York.

Lennox, D. H. and C. N. Kelber. 1956. Summary Report on the Hazards of the Argonaut Reactor. ANL-5647, Argonne Nationat Laboratory, Lemont, Illinois.

Little, W. W. and R. W. Hardie. 1969. 2DB User's Manual - Revision 1.

BNWL-831 Rev. 1, Pacific Northwest Laboratory, Richland, Washington.

Manchester and Liverpool Universities. 1966. Safety Report. Manchester, England.

Miller, R. W., A. Sola and R. K. McCardell. 1964. Report of the SPERT I Destructive Test Program on an Aluminum, Plate-Type, Water Moderated Reactor. ID0-16285, Phillips Petroleum Co., NRTS, Arco, Idaho.

Nightingale, R. E. 1962. Nuclear Graphite, Academic Press, New York.

Nyer, W. E. et al. 1956. Experimental Investigations of Reactor Transients. IDO-16285. Phillips Petroleum Co., NRTS, ArCo, Idaho.

Russe11, C. R. 1962. "Safety Features of Water Reactors." In Reactor Safeguards. Pergamon Press/MacMillian Company, New York.

Saller, H. A. 1956. "Preparation, Properties and Cladding of Aluminum-Uranium Alloys." In Reactor Technology and Chemical Processing, Vol. 9 of Proceedings of the International Conference on the Peaceful Uses of Atomic Energy. United Nations, New York. 
Schroeder, F., et al. 1957. "Experimental 5tudy of Transient Behavior in a Subcooled, Water-Moderated Reactor." Nuc. Sci. Eng. 2:96-115.

Thompson, T. J. 1964. "Accidents and Destructive Tests." In Reactor Physics and Control, Vol. 1 of The Technology of Nuclear Reactor Safety, eds. T. J. Thompson and J. G. Berker ley, pp. 608-708. The M.1.T. Press, Cambridge, Massachusetts.

U.S. Code of Federal Regulations, Title 10, Part 50, "Licensing of Production and Utilization Facilities: (1980).

University of California at LoS Angeles (UCLA). 1980. Argonaut Safety Analysis Report. Los Angeles, California.

University of Florida. 1980. Safety Analys is Report. Gainsville, Florida.

University of Washington. 1960. Safety Analys is Report. Seattle, Washington.

Virginia Polytechnic Institute and State University (VPI). 1979. Preliminary Safety Analys is Report. Blacksburg, Virginia.

Weber, C. E. and H. H. Hirsh. 1956. "Dispersion-Type Fue] Elements." In Reactor Technology and Chemical Processing, Vol. $g$ of Proceedings of the International Conference on the Peaceful Uses of Atomic Energy. . United Nations, New York.

White, 0. W., A. P. Beard and A. H. Willis. 1957. "Irradiation Behavior of Dispersion Fuels." In Fuel Elements Conference, pp. 717-747. U.S. Atomic Energy Commission, TID-7546. 

NUREG/CR-2079

PNL-3691

R1

DISTRIBUTION

No. of

Copies

OFFSITE

A. A. Churm

DOE Patent Division

$9800 \mathrm{~S}$. Cass Avenue

Argonne, IL 60439

270 U.S. Nuclear Regulatory Commission

Division of Technical

Information and Document Control

7920 Norfolk Avenue

Bethesda, MD 20014

Harold Bernard

Nuclear React or Regulation

U.S. Nuclear Regulatory Commission

Washington, DC 20555

Walt Pasedag

Nuclear Reactor Regulation

U.S. Nuclear Regulatory

Commission

Washington, DC 20555

Steve Ramos

Chief Emergency Preparedness

Program

U.S. Nuclear Regulatory

Commission

Washington, DC 20555

R. Wayne Houston

Chief Accident Evaluation Branch

U.S. Nuclear Regulatory

Commission

Washington, DC 20555
No. of

Copies

30 Millard WohT

Nuclear Reactor Regulation

U.S. Nuclear Regulatory

Commission

Washington, DC 20555

2 DOE Technical Information Center

M. A. Robk in

Department of Nuclear

Engineering

University of Washington

Seattle, WA 98105

ONSITE

DOE Richland Operations Office

H. E. Ransom

25 Pacific Northwest Laboratory

LG Faust

SC Hawley (5)

GR Hoenes

RL Kathren (10)

WA Glass

Technical Information (5)

Publishing Coordination (2) 



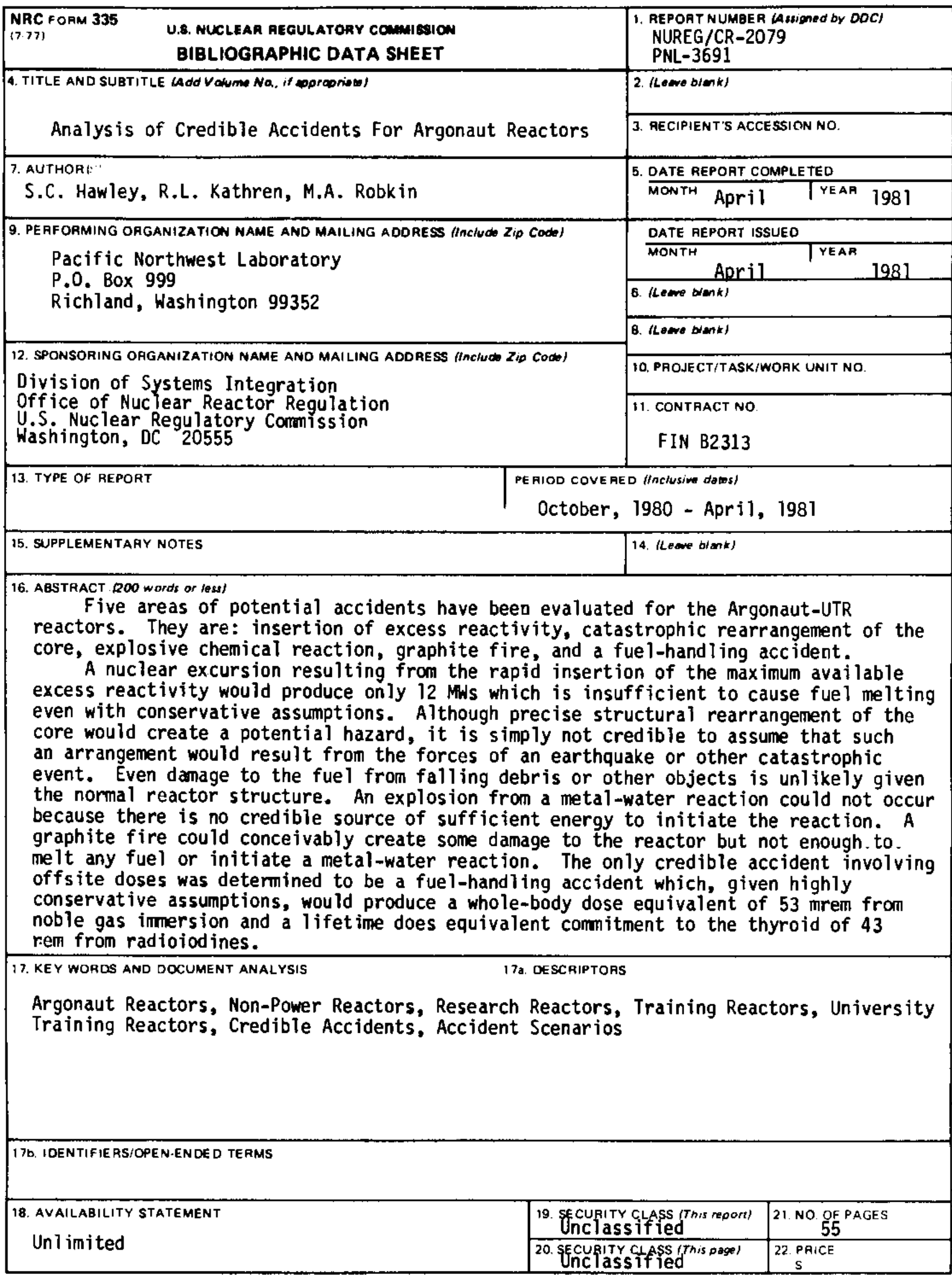


